\title{
Sobre el descubrimiento de la Cultura Chavín en el Perú. (")
}

El presente artictulo es una sinopsis de los estudios y exploraciones qute he realizado durante los últimos años con el objeto de conocer las características te la Cultura Chavin, y determinar su área de propagación en el territorio de los Inkas o clel Tawantinsuyo.

\section{INTRODUCCION}

El año détgigal explorar lacuenca del río Mariastio Pukcha, uno de los tributarios del Alto Marañón, descubrí en Chavín de Huantar los testimonios de una cultura que antes no había sido debidamente reconocicta. Comprobé que ciertas estructuras y otros productos del arte aborigen encontrados altí, correspondian a un ciclo cultural bien ctiferenciado: al re la Cullura Litica de Chavin. Monolitos estatuarios, representando cabezas humanas, de serpientes y felinos; estelas, obeliscos, utensilios diversos, y otros objetos adornados con figtras incindidas o tallaclas, en plano, alto y bajo relieve, representando felinos, serpientes, peces, lagartos y aves fantásticos, constituian los principales elementos característicos de esta nueva cultura, cuya área de propagación

(*) Reproducido de "American Antiquity" Vol, IX, No. 1, Julio 1943, con nuevas ilustraciones. 
sólo se había reconocido por entonces, en las actuales provincias de Huari y Ponabamba. ( $\mathrm{I}$ ).

En los años posteriores de 1919 reconocí entre las colecciones cle antigitiedades peruanas existentes en el pais y en el extranjero algunos ejemplares de alfarería y de oro decorados con motivos de estilo Chavín, tales como un cántaro de la Colección Elías y Elías formada en Morropón, Valle de Piura, (2) otro cántaro en la de Ramón Muñoz de Cajamarquilla, Departamento de Ancasl, (3); varias especies de oro en la colección Dalman de Trujillo, (4); dos cántaros en la de Lizandro Velez López de Trujillo, (5); una olla en la de Máximo Neira, también en Trujillo, (6); un cántaro en la de Antonio-Raymondi, hoy en el Museo de la Universidad, (7);

(1) Tello Intraducción a la Historia Antigua del Perí, Lima, 1921, Lám. VI, VII y VIII; y "Wira Koc]a", INCA, Vol. 1, No. 1, pp. 93,320, Lima, 1923.

(2) La coleceion wilns eonstaba de 1,200 ejemplares procedentes on su nayoría de los antiguos cementeriog del Valle the Piura tin ella encontré un éntaro de eolor elocolate, gollete argueado, figurando una taza llena de frutos pirifortues. La cara cxterna arionalia con figuras incisas de estilo Clavin. Este ejemplar se lialla hoy en el Alugeo de Arqueología PeI uang (Sp. 1/2905). Vease fig. 79 ie Melans, Ancient divilizations of the Andes, New Fork, 1931, $y$ sus similares em fig. 4 , Lam $X$, de Dongld Calliar y Jolun V. MLurra: Survey and Excavations in Southerm Ecuador, Anth. Se, Field Mngeum of Nntural History, Vol. 35, Clicago, 1943; y los ejemplares ecuatorianos que Jijon y Caamaño $y$ Uhle consideraron como representativos de la infinencir Maya en el Eeuador: J. Jijon y Oamaño: Una gran Marea Cultural en el N. O. de Sud Amériea, París, 1930; y Max Uhle: Las Antiguas Civilizaciones de Manta, Bol. de la Acad. Nae. Fist. Vol. XII Quito, 1931; e Influencias Mryas en el alto Ecuador, Bol. Acnd. Nac. Hist. IV, pp. 205-240, Quito.

(3) Sp. 1/1132, Museo de Arqueología de la Universidad.

(4) Ein su mayoría discos somejautes a lns placns-pectorales, tinkurpa o tinkullpa. 13stas especies fucron publicadas por vę primera en el libro El Centenario, eclitado en Italia con motivo del Centenario de la Independen. eia del Perf.

(5) Las execlentes fotogratias de estos ejemplares suministradas por el Dr. Velez so hallan ell al Arehivo del Instituto de Investigaciones Autropologieas.

(6) Neirn la extrajo del Cementerio "El Cortijo" de Chazchan en 1919.

Véase figa. 71 y 72 de Antiguo Perú del autor.

(7) $\$ \mathrm{pp}, 1 / 1133$. 
varios ejemplares de cerámica y de piedra publicados en las conocidas obras de Charles Wiener, (8) ; y Max Schnidt, (9) cos cántaros rotos hallados por Max Uhle en una de las tumbas abiertas por él frente a la waka de la Luna en Moche, (Io); y varios ejemplares — en su mayor parte publicados ror mi--en las colecciones de los hermanos Victor y Rafael Larco Herrera de Trujillo, ( I r ) ; Aclemás reconoci testimonjos claros del arte Chavin en varias piezas de oro y de cerámica descubiertạs por lus hermanos Gayoso en Chongoyape, (Lám $\mathrm{r}$ ), ( ( 2) y un ejemplar de Concha Strombus ex-

(8) Pérou et Bulivie, T'aris, 1880, p. 603. Jal c.jemplap ilustralo eu este libro.es anflogo al otra eneontrado por Uhle nu Moche.

(9) Schunidt Max: Kunst unil Kinltur von Perú, p. 10̄o, fig. 2; p. 211 y p. 462 , fig. 3 .

(10) Journa de la Société des Americajnistos de París, e. 3. X, 95-11\%; $y$ en A. L. Kroeber: Tho Uhle Pottery collections from Moche, Univ, Calir. I ub. in Minur: Areh, and Ethn. XXI, plate 57, figs. J, 1 .

(11) Reproslucidos en gu mayor parte por Tallo: Antiguo Perí, Lima, 1989, figs. 60 al $70 ; 73, y+74$ al 77 , hes cues so eneuentian an el Museo de Arqueolo. gin Peruana.

(12) Jil año 1928 J'loro Mforrofú de 10 nños de edal en compañia do otros mãos menores thus á! encontió en el fomdu de lun zanja abierta por el rebalsu de una aecquía tarios ubjetos de oro, en la hacienda Almendral, de los licrmanos Gajoso, de Chongoyrie. Mforrofístecogio los objetos y se fuso de inmediato $\dot{a}$ jugir con ellos, distribuyendo las piezas halladas entro sus eamarnilas; a uno le ealó una corona, o otro una pulselón y el se puso en las piernas a manera cle politinas, las lóminas eneartujadas, restos de grandes Finos. Vino $n$ interrumpir el inoceste ejtretenimiento de los muehachos, is preseneia a eaballo, de uno de los señores Gayọso, quién atráldo desde lejos por el brillo clel metal que lueian arjuéllos se acercú $y$.conveneigndose qư егал de oro, trató de adquirirlog. Fué dijficil para Gayoso reunir todas las expecies del liallazgo; unos le obseyzataton y reciljeron una modesta gritifieneion, otros huyeron llevando el oro $n$ sus padres o a las liendas para eanjearling con bizcochos.

Es así como algunis piezas llegraron a poiler de los joyeros y de otras jersonas, de quienes Gayoso las recupero con graudes estuerzos. E'l mismo вeũor Gryoso, pocó después liso un nuevo. liallazgo tan importante como el anteriar, $\Lambda 1$ prateticar una excavación, con el objeto de reforzar el resorvorio de agua potable de Chongoyapo, encontró a tres metros de profundidad tres calávereg cehados. Entre cada uno de ellos halle restos de cenizas $y$ tierra guemida que parecian correspouder a fogatas hechas al tiempo de in inhts. maciún.

Juato a los piés la lus calúveres encontró varios wukos y entre ellos una precioga fuevte o bandejn; pero lo más notable de estẹ hallazgo fueron los 

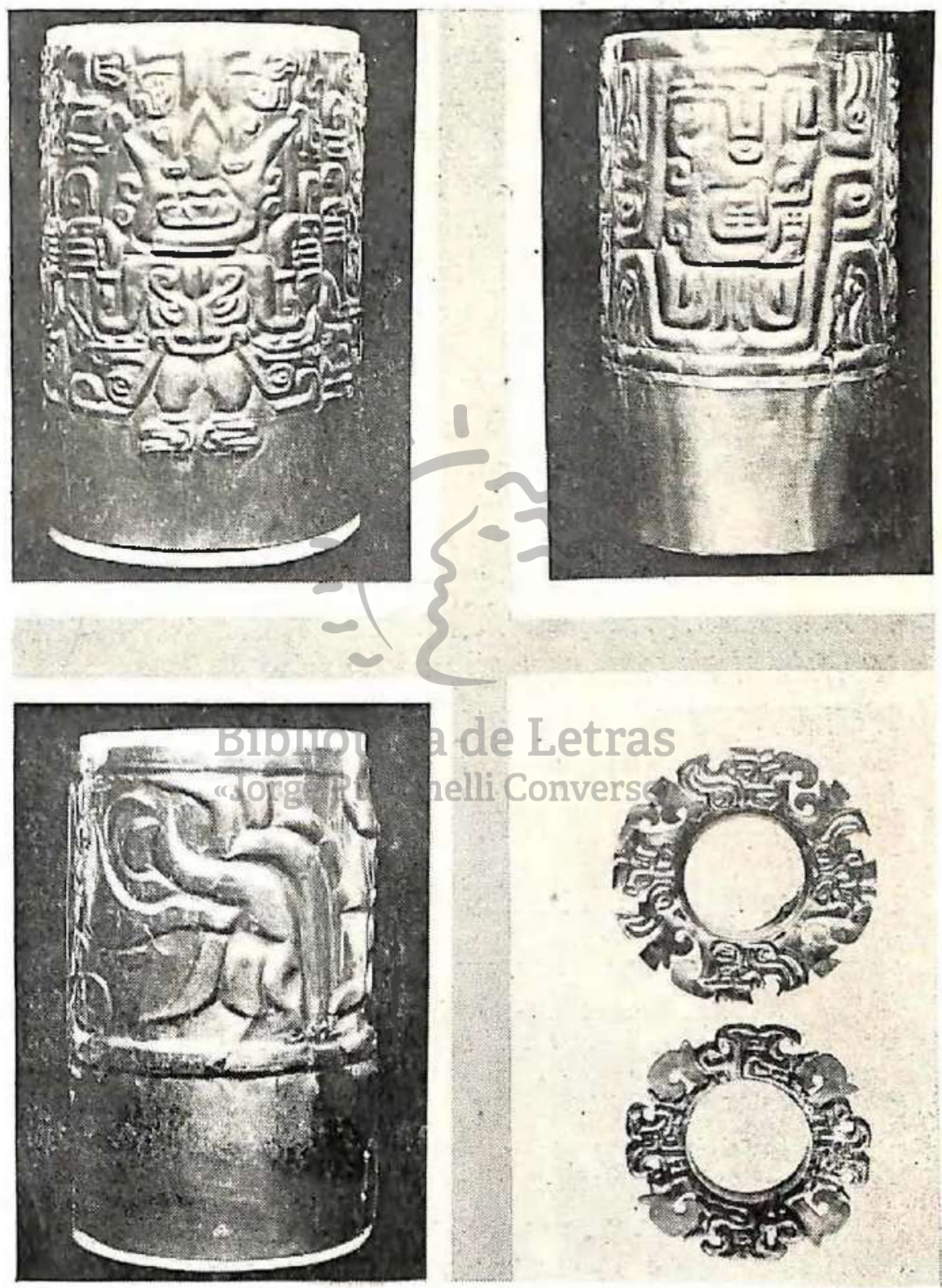

Objetos de oro rle Chongoyale, Lambayegue. Museo del Indio Americano. Heye Foundation, New York. 
部 
traida por Abraham Pickrian al cortar un monticulo situado cerca de la base aterea de Chiclayo. (Lám. IV, V), (I3). $A$ mediados de 1925 descubrí en los basurales y cavernas funerarias de Cerro Colorado, Península de Paracas, una nueva clase de alfareria ornamentada con los mismos motivos, y trabajacla con la misma técnica del arte Clavín, aúnque con el agregado de nuevos elementos tipológicos que la

br:izaletes, surtijas y prendedores de oro que teaian los eadiveres certa de las manos. La colesçín Gayuso se halla en ei Mfuseo Iudiano cle Nueva Fork. $\Lambda$ raíz de su deseubrimiento fué fotografiado y reproducida eu Antiguo Perú de Tello; $y$ la sido motivo de la monografia de Samuel $K$. Lot]irop: Gold and Orunments of Chavin Style frown Chongoyape, F'erú American Antiquity Vol. 6, No, 3, 1941.

(13) "A fines dol mess cle Enero le 1937 cncontrándome en Clielayo, faí informado de que el Comandante de Aviación don Abrabam Pickman poseía un ejemplar de roneha mariua decoraila bon figuras ineisas, la cual ha. bia sido extraida al practieurse un trabajo de nivelneín del suclo en las recindadey de la Base Aeren de anuella ciadad.

"Ha conchn ex la de un molusco dic la especie strombus galentus. Es un hormoso ojemplar do color perla con juspes sepia (longitud 23 em.; ancho

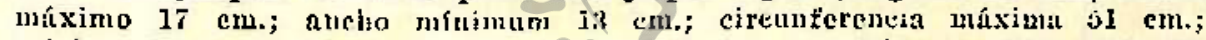

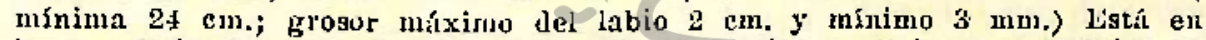
buen estalo de conservacion, salvo ligerias erosiones en la cara snferior nó decoradr. Ha sido adajtada para su uso como instrumento cle curáter sagrado o ecremonial. bil ipix está perforado las espiras dorporales o eustillus

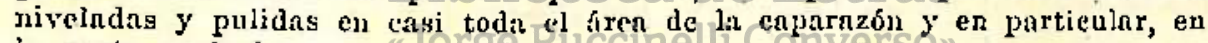
la parte gribuada.

"Corea del bordo de la espjira extrena buy uma perforación, siu duda, para el paso del corclón que tacilitaba su uyo como instrumento portátil. Lis concha on cuestion, es la trompeta de earacol marino o churu que desda If mís remota autigüedai usaron los peruanos en sus ceremonias religiogad. fu la época de la conquistic espantiola dos indios del Perú designaisan a esta chase do trompetas con las denominaciones de Pututu $y$ wailla kepa.

La decoración consigte on un panel que ocupa la eara enperior de la eoncha, En ella aparece representala mediante líneas incindidas uma divinidad en actitud de soplnr la trompeta strombus, bin ei rondo aptrecen sępientes entrelazadas furmando nulos dispuestos gimétricamente en pares a uno $y$ a otro lada de la figura central. Dichos nudos simulan a la tex eabezas entrelazadas de jaguares. (Una recoustruceión de la manera cómo se digponen estag cabezas ge ofrece en la figura 2 .).

"La divinidad representada es el jaguar humanizedo que comunmente apareé en el arte elásico de Chavin. La humanización del jagunt es aquí mauifiesta. En Chavín por lo general la fiern tiene los pelos trangformados en sorpientes; el cinturón y las ajoreus en cabezas estilizadas de jaguar, y los detalleg somficicos son francamente felínicos. En este ejemplar los carateres humanos soo más resaltanter que los felfuicos: la eabeza, el ojo, los de. 
vinculan genéticamente con la clásica alfarería de Nasca, tales como las formas globulares derivadas de los tipos de lagenas, los golletes tubulares imitando huesos de aves, y la pintura policroma a base de tintes oleosos o resinosos. (14).

En los años de 1926 y 1927 al hacer una revisión de los trabajos de Max Uhle, con el objeto de valorizar los fundamentos de su teoría sobre el or igen y desarrollo de las Culturas Peruanas, descubrí con sorpresa que los restos de alfarería hallados por él en los basurales de Ancón y Supe no eran otra cosa que restos de la alfarería clásica de Chavin. Uhle creyó que esos restos de alfarería hallados pertenecian a una cultura primitiva de pescadores caníbales que, según él, fueron los pobladores del Litoral antes de la aparición de los pueblos que trajeron del exterior las culturas adelantadas de Proto-Chimú y Proto-Nasca. ( I5).

La Cultura de Chavin, a pesar de estos hallazgos dispersos, no se había logrado individualizarla dentro de una verdadera enticlad cultural. Sus escasos y esporádicos elementos integrantes parecían no tener uma vinculación directa e immediata. Por ésto, los pocos testimonios conocidos

talles de la boca y el cabello fon humanos; pero la nuriz en felínica. Lil enerHo $y$ extremidades auperiores humanos, y las extremidades inferiores $y$ las patas felinicas.

"El uso del strombur en las prícticas religiosas judianas es muy anti. guo en el Perń; se le puede seguir a través de las grancles eras cio la ovolncion del urte aborigen. Este ejemplar viene a sumarge al encontrado en uni tumba Chavía del templo de Punkuri, valle de Nopeña.

"La importancia de esta especie, estriba, prineipalmente en la peculiar decoracion que presenta en su eara externa". "Tomado de Tello: El gtrombus en eí arte Chavin", Lima, 1937, con dos ilustunciones,

(14) J'ollo "Los Descubrimientos del Museo de Arqueología Peruann an Ia Feningula de Parnen" Strntto de Atti del XXII. Congreso Interuazionale degli Amer. Roma, Setiembre, 1926.

(15) Con motivo del descubrimiento de templos Chavín en el Vahe de Nepefa, yo hice la higtoria de los principales hallazgos e identifieaciones de cerfimica Chavín en la Costa en varios artículos titulacios "Las ruinas del valle de Nepeñn", "Gi Comario", Lima, 6, 9 y 14 de octubre de 1931. 
del arte de Chavin, se consideraban unas veces dentro del dominio de la cultura de Tiahuanaco, otras dentro ciel de Nasca, siempre como expresiones de otras culturas ya identificadias.

\section{VALLE DE NEPENAA: CERRO BLANCO Y PUNKURI}

En 1933 descubri en el valle de Nepeña dos magnificos exponentes del arte Chavín: los Templos de Cerro Blanco y Punkuri. Por vez primera yo probé que los restos de la civilización de Chavín, yacían sepultados bajo los escombros de las estructuras correspondientes a las culturas Muchik y Chimú consideradas hasta entonces como las nás antiguas y adelantadas de la Costa peruana. ( 16 ). (Lám. II, a).

Las excavaciones realizadas en los monumentos altdidos aportaron nuevos datos acerca de los caracteres de la cultura Chavín en su adaptación a las condiciones físicas de la Costa, de sus dos faces o etapas de desarrollo yt dest gran antiguiedad. E1 Templo de Ceren Blanico había sido senultado por una gruesa capa de lodo-restos de antiguas inundaciones-, sobre la cual se cultiva actualmente caña de azúcar. En algunos sitios cubrian el templo dos tipos de estructuras diferentes: uno que parecia ser sólo una nueva faz de la propia cultura Chavín; y el otro que correspondia a los edificios, tumbas y basurales de las gentes que vivieron alli tulteriormente. En el piso inferior, las construcciones eran de piedra; las paredes estaban revestidas con barro, y adornadas con figuras en

(16) La historia del deseuhrimiento de los Templos de Cerro Rlanco $y$ Punkurí en Nepeña, $y$ de todos los restos Chavín ballados basta entonees en la Costa, la di a conocer al público a raíz de los hallazgoe en los perídicos de Lima. 
relieve, admirablemente modeladas en arcilla fina, y pintadas con múltiples colores imitando las esculturas liticas del arte Chavin. En el rẹleno de los edificios destruidos y habilitados como subestructuras de otros celificios, se encontraron algunos fragmentos de vasijas negras del tipo clásico Chavin. En el piso medio las construcciones eran de piedra y de adobes cónicos pequeños, y las paredes emmastadas, enlucidas y pintadas. En los escombros de los edificios que sobre este piso se levantaron y que llenaban las habitaciones, no se halló fragmentos de alfareria. En el piso superior se encontraron los restos de las viviendas, la bastura y las tumbas de las gentes que yivieron alli utilizando en sus construcciones los materiales empleados por stis antecesores. Dichas gentes pertenecín a la cultura representada por las vasijas policromas de los tipos Santa y Nepeña último, cnetáneas del Chimú.

En el Templo de Punkuri se repetía casi en su integridad el mismo fenómenot Laxwaka ha sidosalguna vez scpultada en gran parte por una masa de lodo que parece haberse extendido por todo el valle. El piso inferior contenía cstructuras de piedra con, paredes ornamentadas en el estilo clílsico Chavin. Estas estructuras fueron derrumbadas, y utilizadas después como fundamento de los nuevos edificios del piso medio, y éste, a su vez sirvió para los del piso superior. Como en el caso de Cerro Blanco, en los dos pisos inferiores se encontraron restos de la cultura Chavin: un ídolo hecho con piedra y barro, representando en bulto la figura đe un felino pintado con diferentes colores; una tumba conteniend. el cadáver de una mujer sacrificada, en asociación con una concha caracol (Strombus galeatiss), un pañito recamado con:laminillas de turquesas, y un mortero provisto de su 

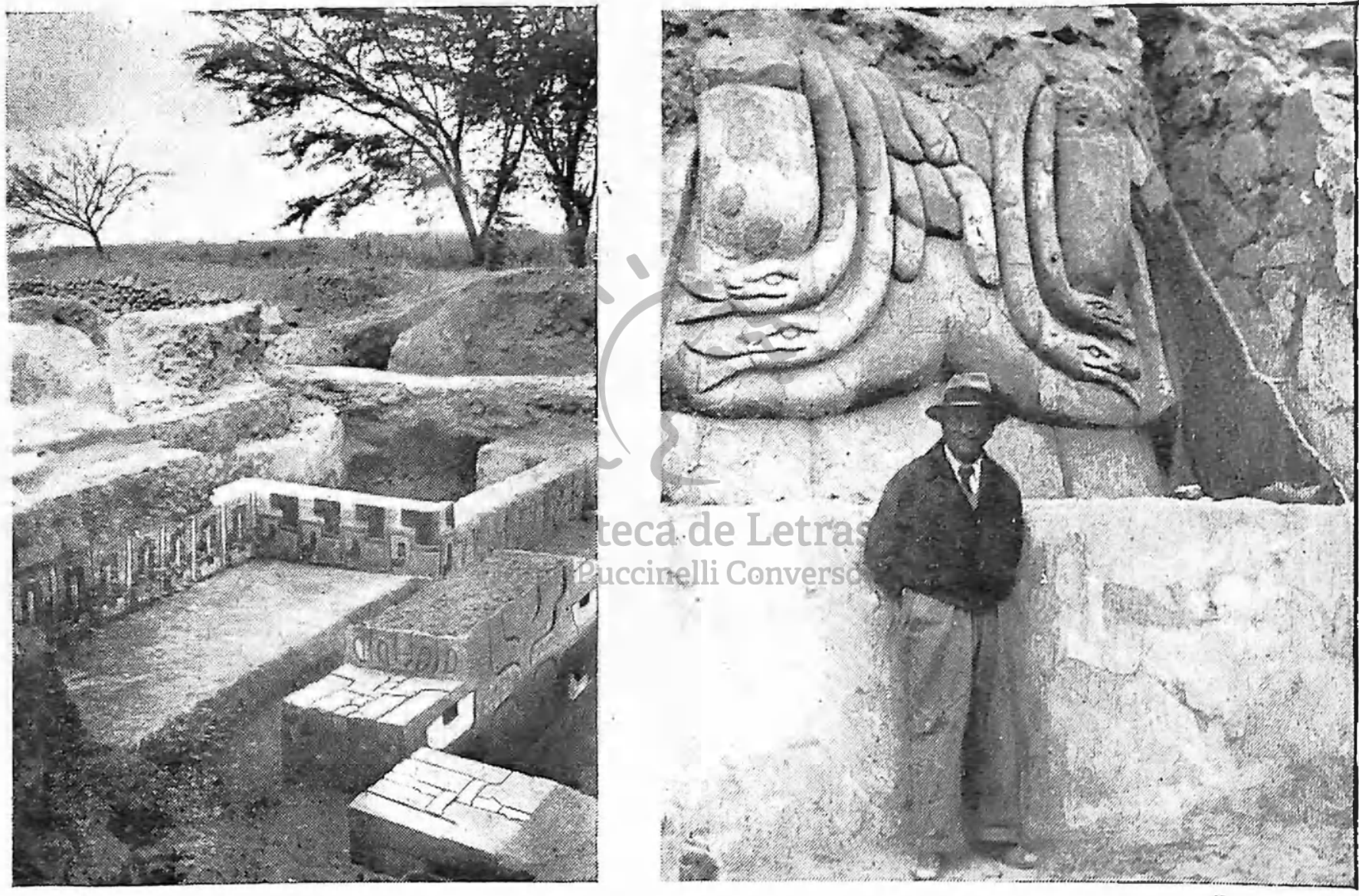

a. Tua sectión del Templo de Cerro Blazeo después de las exctvationes de 1933, Nepeña.

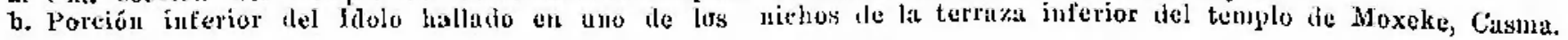




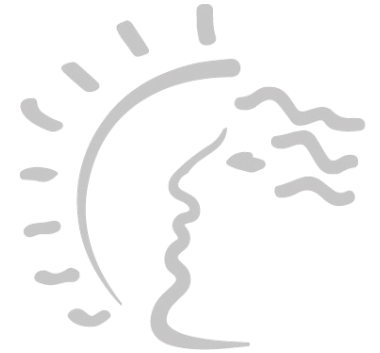

Biblioteca de Letras "Jorge Puccinelli Converso» 
respectivo pisón, ambo: cle ciorita, y pulido y grabado con ijguras en el estilo clísico Chavin. En el piso medio las estructuras tenian las paredes fabricatas con adobes cónicos y adornadas con figuris incindidats y pintadas sobre tuna superficie previancule culucidal y restos de varias cámaras soterrados con pinturas murales (Lám. III. a). Solue es1c piso se encontraron tanbién restos de vivicndas, basura y algunas tumbias de los periodos últimos Santa, Nepeña y Cllimú.

En consecuencia, en Nepeñil quedó plenamente probado que la culcura Chavin se habia propagado a la Costa y adiptado a las concliciones propias del nuevo medio. In la princra etapa de esta adaptación habia mantenido ficlmente las caracteristicas fle la cultura originatria; y en la segunda se habia morlificado consiclerablemente. Asi, lis construcciones en la princri clapa eran exclusivamente de piedras, estaban adornadits con liguras que reproducian fichnonte las enpleadas al lats ornamentaciones en piedra del templo de Chavin. En lat segrundis etapa las buistutediones ertat deadobes cónicos, initando, sin ctuda, dase piedras enincitorues empleadlas en las anteriores, $y$ las ornamentaciones pintadas con ligntas que initan las grabadlas y un relieve del arte lítico originario.. En la tercera elalya clesaparecia por completo todo elemento caracteristico del arte anterior; las construciones cran de adebes rectangulares con paredes enlucidas y adornadas con figuras correspondientes a un arte completannerlte ntievo. Lats estructurats de este periodo stabsisticron segoramente hasta la concutista españolid.

La explenación del valle de Nepeña, descle la Bahia de Samance hiasta los confines de lat región cisindina, pernititió reconocer con cierta aproximación las principales caracteristicas de las culturias alli existentes, entre ellas $\underset{\substack{\mathrm{g} \\ \mathrm{g}}}{\cos }$ si- 
guientes: I. - Ruinals de poblaciones, unas construiclats con adobes rectangulares hechos a molde, otras con piedras pequeñas y barro, y cententerios en las vecindades de ellas, eon un conteniclo mas o menos uniforine, todo correspondiente a la última ctapa de ocupación del valle, y ubicadas de trecho en trecho a lo largo de las hoyadas marginales. 2."- Pirámides escalonadas en asociatión con otras estructuras rle amplias habitaciones rectangulares, construidas con adobes, y adornaclas, en parte, con frescos policromos representanclo escenas guerreras o mitológicas, semejantes a las que ornamentan las vasijas Muchik, y cementerios en las vecindades con tumbas. superpuestas y con 111 conteniclo más o menos uniforme, difícil de diferencial en stis dos etapas de desarrollo, porctue la última parece ser simplemente una cotitinuación de la anterior. Existe un nismo tipo de alfarería que corre a través de las dos etapas manteniendo sus características morfológicas y mannentajes con la sola diferencia de un clecaimiento cn caliclad, clel arte en la última etaj)a. 3."-Estructuras de pier!ras completamente distintas en estilo de las anteriormente mencionadats pero scmejantes o iclenticas a las megalíticás anclinas, cono las de Kusi Pampa, Pincla Marka, Kiske, Waka Particla, Paña Markä, y la segrunda. Waka de Cerro Blanco. En la parte inferior del valle estas estructuras se encuentran sepultadas por las otras de eclad posterior; y en la parte superior estáln clescubiertas, y tan puras en su estilo que se continúan al parecer sin cliferenciáción alguna hasta el Callejón cle Huaylas; y, por último, en las estructuras de este tipo arcaico ubicato en la partes bajas se destaca el estilo característico de la arquitectura Chavín. Las wakas están construiclas mediante plataformas superputestas, comtunicaclas por galerías, con restos de altares, colimnas, y paredes profusamente aclornactas con figuras modelatas o pintadas en barro en el estilo de las figuras graba- 


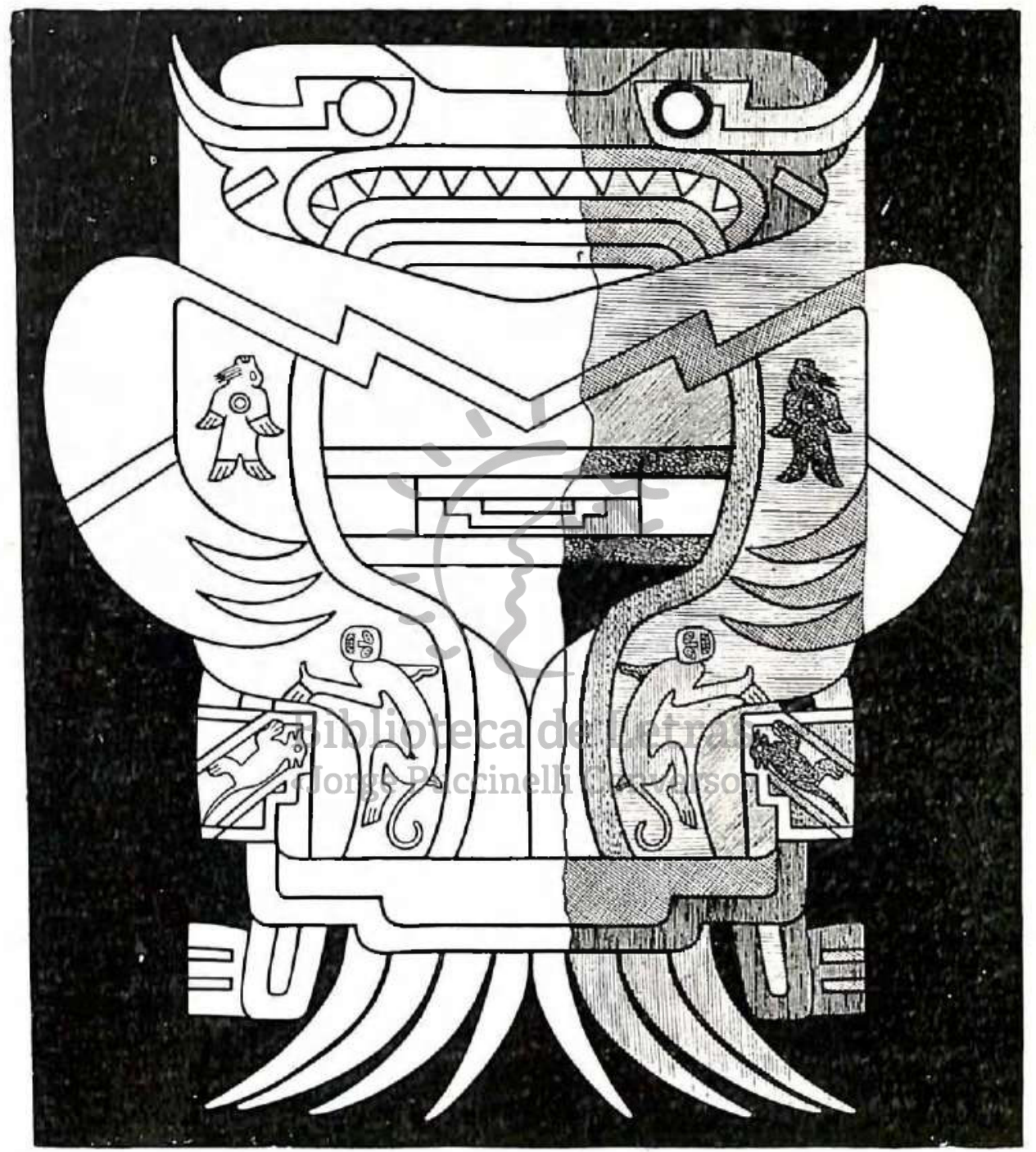

Fresco mural que adortia una de las pamaras soterraclas del Templo do Punkuri, Nepeña, dessubierto en 1933. 


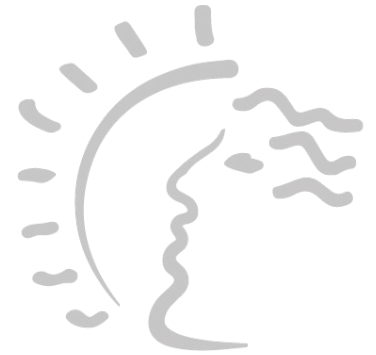

Biblioteca de Letras "Jorge Puccinelli Converso» 
clas en piedra de Chavín de Huantar. Se emplea en ella el aclobe cónico de diversos tamaños, descle $0.20 \mathrm{~cm}$. hasta 0.80 $\mathrm{cm}$. de alto para la construcción de las paredes y del relleno de las plataformas.

Antes del clescubrimiento de la cultura Chavín en el valle de Nepeña se podía pensar - a base de los escasos y aislados hallazgos de restos de alfareria-, que las viejas poblaciones trasandinas se hubicran infiltrado incidentalmente por las tierras bajas del litoral o de la montaña, a la manera de colonias temporales o migratorias. El descubrimiento de Nepeña vino a aclarar de manera definitiva el vercladero carácter de la cultura Chavín en la Costa. Ein primer lugar, sc comprobó que esta cultura era rica en elementos representativos, inconfundible en st diferenciación e icléntica a la trasandina en sus rasgos característicos esenciales. En segundo lugar, se clemostró que sus restos ocupan el estrato más bajo entre los estratos correspondientes a las culturas consideradas por otros investigadores como las primeras y más antiguas del Perú. El hombre de Chavín ctesarrolló en el valle de Nepeña sobre unetereno airgen una civiiización que no tienerantecelente, litantovporosu originaliclad como por la excelencia de su producción artística. El mismo estilo arquitectural, el uso de la misma clase de motivos decorativos y simbólicos y uni manera peculiar de aprovechamiento de los recursos del medio, adaptáundolos a las normas pre-estableciclas, dan fisonomía propia a la cultura de Chavín.

En poscsión del material que permitió diferenciar tal cultura se hizo necesario, en consecuencia, clirigir la investigación en el senticlo de conocer mejor sus característicás e indagar acerca de sus contros originarios de difusión. Estas consideraciones me condujeron a explorar el va- 
lle de Casma por su esjecial situación geogrática, en primer lugar, c hicicron asi mismo indispensable el reennocimietrio de la región de vertientes de la Cordillera Negra y del Callejón de Huaylas en segundo lugar; porcue en ambatis regiones los restos de la cultura de Chavín debían hạllarse debajo de los estratos correspondientes a lits culturas que parecen ser alli las predominantes y las más antiguas.

\section{VALLE DE CASMA : EL 'PE'MPLO DE CERRO SECHIN}

Durante da segunda mitad del año de 1937 luí comisionado por lis Universidad de San Marens de Lima para realizar un reconocimiento arqueológico del Norte Pertano, y estudiar de preferencia los restros de las civilizaciones más antiguas que encontrara a través del territorio, entre la Costa y la frontera amazónica. La expedición erutipada con este objeto se realizó gracias al apoyo prestado por el Institute of Andean Research de los Estados Unidos, y por el señor Nelson A. Rockefeller

Fuí acompañado durante todo cl viije por los señores Toribio Mcjía X., Pectro Rojas y Hernan Ponce, empleados del Museo de la Universidad de San Marcos, por las señoritas Honour Mc Creery y Bárbara Loomis de la Universidad de Nuevo México, y durante tres meses por el señor Donald Collier del Institute of Andean Research. También prit dos semanas se agregatron a la Expedición los jóvenes istucliantes Edward Mc Cormick Blair y Deering Danielson.

Entre los sitios más importantes reconocidos por la Expedición figuran las ruinas de Sechín, Moxeke y Pallka sithatas en cl valle de Casma e iclentificadis como corresponmenclientes a la cultura de Chavín; cl acueducto megalítico te Kumbe Mayo, cerca de Cajamarca; los mausoleos mega- 
líticos de Yanakancha cerca de Hualgayoc; las ruinas megalíticas de Kochabanba en la Provincia de Chachapoyas; las ruinas de Cholita en lit Provincia de Celendín; y las de Nunamarka cerca de Chilial, en la Provincia de Patalz. Exceptuando las del valle de Casma, todas ellas se hallan dentro de la cuenca clel Marañón.

El informe integral de las exploraciones realizadas por la expedición arqueológica al Maranón contendrá los testimonios que prueban la extensa área de propagación de la Cultura cle Chavin por la sierra y la costa peruanas. Por ahora me limito a dejar constancia del descubrimiento de los Templos de Morcke, (Jám. II. b.). Pallka y Scchin. en el valle de Carsma, algunos de los cuales, como el de Sechín, estín adornados con esculturas monolíticas clel estilo Chavin.

Cuando en julio de 1937 visité por vez primera la Waka Cerro Sechin que se halla situada al pié de la falda N. del peñón llamado de "Los Corrales" o "Cerro Sechín", a cerca de siete l:ilómetros al oriente de la ciudad de Casma, me llamó la atención de cue a lo largo de la margen anterior de la hoyada donde sd Gallada dvaka Gapureieran enfilaclas cinco estacas de piedga easicin dinearecta, a florando apenas a la superficie, tres hácia el $\mathrm{E}$. juntas y dos alcjadas entre si, hácia el $O$. Inspeccionando los alrededores de la Waka descubrí adenuás, que dentro de los terrenos de cultivo yatcían otras pieclras seni-sepultaclas que presentaban figuras grabadas en una de sus caras. (Lám. VI, a.).

Las estacas probaron corresponder a unidacles mayores sepultallas bajo una gruesa capa de tierra suelta, y todas ellas presentaban también en una de sus caras figuras grabidas que eran a la vez partes de otras mayores que se percliam en lat profundidad.

Con el fin de adquirir uma información más concreta 
acerca de la presencia cle cstas piedras, en un lugar tan extraño como éste, orienté los primeros trabajos en el senticto de clesenterrar primero todas las piedras sepultadas por la tierra suelta o tierrá de desmonte.

Mi primera impresión fué que estas piedras hubieman siclo extraíclas de alguna otra estructura más antigua del Templo de Sechín Aito, por ejemplo, y traídas aquí por otras gentes y por motivos semejantes o diferentes a los que determinaron su uso original. Pronto me convencí, con el descubrimiento de nuevas estacas, que ellas seguían una línea contíntua, con cortos intervalos vacíos. Pensé cntonces que estas piedras formarían tal vez parte de un monumento semejante al recinto o plaza de Kalasasaya de Tiahntanaco. Esto me obligó a ahondar la excavación por el laclo N. de la hilera, a fin de alcanzar cl piso sobre el cual se levantaibin. Para ello dividí el cimpo ojeratorio en secciones de a $4 . \mathrm{m}$. cada ina, a fin de observar prolijamente los inciclentes y retalles cle la posición, forma, magnitud y ornamentación de ias pieclras, y ala vez adrutirir datos sobre la estructurá del terreno donde estaban scipultadis. Mientras, por un lado, se climinaba cuididosamente fi cipa de tierra suelta del piso superior que no conteníi resto arqueológico alguno, hice practicar alrecledor de la piedra hallacla en el extremo Oc. cidentai un corte a pique siguiendo muy de cerca las caras de la piedra. Escogí este sitio porque cletrás de la estaca de piectra, allí encontracla, había tuna extensa depresión del terreno como de clos metros de profundiclad y de tres a cuatro metros de dímetro. Con facilidad se eliminó la tierra y pieclras que ocultalian al nionolito por clelante y detrás, y se alcanzó la base o extremo inferior de éste observálnclose que estaba ligeramente inclinado sobre un montón de pieclras colocadas por delante a la manera de cuñas y que presentaba 
una fïnura grabada en plano relieve, un ser fantástico especic de engendro humano y felinico por ciertos de sus caracteres, con el cabello erizaclo y clesgreñado, por ctya razón, sin cludia, las gentes del lugar llamaron a este sitio el de la "Waka del Indlio Jravo".

Ia excilvación fué fácil por cietráls del monolito. Se extrajeron las piedras anontonadas alli y la tierra stuelta hastil alcanzar la base por ese lado a dos metros de profundidad. Por la cara anterior y por los lados derecho e izquierdo de él, el trabajo fué más laborioso. Por la primera, la piedráa clescansaba sobre un terreno sóliclo de barro endureciclo como concreto con algunas piedras incrustadas dentro de ci. Por los laclos, lia base del monolito estaba acuñada por muchas piedras pequeñas encajaclas entre él y los ctros monolitos grandes contíguos. Para facilitar el trabajo y el aislamiento completo de açuél se proceclió a enderezarlo e inclinarlo ligeramente hácia atrás. Sólo entonces se logró separar las piectras sobre lis que se apoyaba. Dicho montín ocultaba a la vexótro peeneño. Ampliando la excavación de E. a O., se descubrió a cuno y otro liclo del monolito del Indio Bravo otros tres de la misma forma y tamaño. Los cuatro ostentan en una de sus caras cabezas humanas gralacklas.

A pesar de que en el fondo mismo de la excaración se encontraron dos monolitos pequeños en posición vertical $\mathrm{y}$ en la misma línea del primero, no se observó dato alguno cie importancia que permitiera explicar la curiosa posición de estas picdras. Sin embargo, uno de los pequeños labía dejaclo en el barro sobre el que cayó la impresión níticla de su cara grabada. Este hecho revelaba que los monolitos en este sitio habían siclo inclinados, volteados o arrastraclus a cieria distancia por una masa de lodo prodtucicla y removicla de la 
parte superior de la hoyada. E! terreno, por lo demás, estaba compuesto por un conslomerado de piedras pequeñas minidas entre sí, por tma especie de arcilla brtma numy clura.

El trabajo se realizabal sinultineamente botrats secciones con el propósito de separar sólo la capa superticial y ubicar los monolitos existentes. Algunos oftes fueron descubiertos, notándose que guardaban uniformemente unat marcada inclinación hacia adelante. La excavación se contintó, Ilevánclola en profundiclad hasta el piso correspondiente a la platáforma sobre la que se levanta sl muro de monolitos. Halcia el oriente la renuoción fué laboriosa a cansa de lat gran canticlacl de tirräa suelta alli acumulada. Para alcanzar la base o extrenielad inferior de las piedras, se hizo necesario climinar esta tierra en 1 volumen considerable, el cual crecial a medicla qute la excavación avanzaba hacia el occiclente. Ademís, a poca profundiclad, aparecieron multitud de pieclas que cubrian casi totalmente los monolitos. Cómo en el extremo ojuesto, los mayores y menores guarolaban la mismat posicion telativas tos primeros testaban inclinados o echados hacia adclante; los segumos csitaban intercalades entre arpucllos. Entre éstos los que estaban al mayor profundidad, se hallaban colocados rerticalmente o con una ligera inclinación hacia adelante, y los que seguramente estuvieron encima de éstos fueron hallados it uno, dos y tres metros más adelante: monolitos menores clebajo de momolitos mayores, como si un cataclismo hubiera saculido el monumento con tal fuerza que las enúas liklerales e inferiores se clesprendieron produciendo el derrumbamiento. Con todo, la solidez de la construcción en este laclo debió ser mucho mayor que la del otro, porgue quedan todavia aqui restos del primitivo mutro, bien formado, anmote todas las piedras superiores están fuera de su sitio, las inferiores a- 
parecen fuertemente engastadas sobre todo en la sección correspondiente a los intervalos que separan los monolitos mayores. Además, la fuerza destructiva debió actuar con mayor intensiđad por la parte alta que por la baja, porque sólo así se explica que la mayoría de los monolitos mayores se hubieran inclinado o caído hacia adelante.

En el lado oriental, mejor que en el occidental, la excavación ofreció datos muy ilustrativos acerca de la estructura del terreno cortado. A cierta profundidad, después de eliminada la capa de tierra suelta mezclada con ripio y arena, se encontró una đelgada capa de basura que corría oblicuamente por delante del muro. Dentro de esta capa aparecieron fragmentos de alfarería policroma y algunos esqueletos humanos y de perros, Esta capa engrosaba, y asumía una posición francamente horizontal cuando el corte avanzaba por encima y por detrás de la hilera de monolitos. Tan pronto cómo se notara que el terreno mantenía en este sitio un carácter estratificado, se procuró evitar, en lo posible, el derrumbe de la capa superior y ahondar la zanja por delante. Fué así como se pudo seguir la excavación en una longitud de veintitrés metros, desde una depresión que aparentemente marca el límite Este del muro hasta la piedra que se destacaba sobre la parte mas alta del desmonte.

Durante el proceso de la excavación se fué observando que los monolitos descubiertos en un lado parecían ser gemelos de los del otro, de modo que el edificio podría tener dos alas simétricas: izquierđa y derecha, y tal vez una entrada al centro, marcada por la piedra más alta. Esto me indujo a continuar el trabajo por el lado izquierdo $u$ occidental y definir el curso del muro. La excavación por este lado fué $\tan$ interesante y $\tan$ llena de sorpresas como por el otro. Para adquirir mayores datos sobre la estructura del terreno y so- 
bre la exacta ubicación de las piedras grabadas, hice ampliar el campo de operaciones así en extensión como en profuncidad. Para no perder detalle alguno de importancia se separó primero sólo la tierra suelta de la superficie, enseguidla se fué examinando el terreno a medicla que se le cortaba a lo largo de la zanja abierta de oriente a occidente.

Eliminada la tierra suelta de la superficie aparcció, como en el otro lado, la masa compacta de piedras y barro y dentro de ella las piedras grabadas. Tarea difícil fué separar este conglomerado para descubrir los monolitos. Aquí mejor que en la sección derecha las piedras que cayeron sobre el barro dejaron en él la impresión de sus grabados; y aquí también los testimonios que la excavación ponía a la vista eran mucho más ilustrativos y atrayentes, porque se podía contemplar los estragos y magnitud del cataclismo.

Los monolitos mayores y menores fueron encontrándose uno tras otro, los primeros echaclos, o bien muy inclinados; y los segundos arrojados a dos y tres metros fuera del muro. Algunos de los mayores estuvieron fracturados en su tercio superior y algunos de los menores fueron hallados debajo de aquellos. La caida de plano de los mayores permitió examinar el terreno sobre el cual habían sido colocados. Las piedras no habían tenido, en rigor, base firme de sustentación; estuvieron colocadas directamente sobre el piso duro y pedregóso con algunas cuñas a los lados; uno de ellos había siclo colocado sobre un montón de piedras rodadas. (Lám. V, $a$ y $b$ ).

Se procedió enseguida a excavar en la sección central para unir los dos cortes laterales. Esta labor fué algo difícil debido a la acumulación de tierra suelta que en este sitio alcanzaba mayor volumen y a la necesidad de ampliar el campo de la excavación en una área mayor para evitar los 
derrumbes. A cinco metros de profundidad se descubrió la piedra grande gemela de la del otro lado. Estaba echada y cubierta totalmente por una gruesa capa de piedras y barro. Este monolito tiene la extremidad superior muy desgastada como si hubiera estado expuesto mucho tiempo, y está fracturado al nivel de su tercio inferior en dos partes como si al caer bruscamente hubiera chocado con una pieđra saliente que le servía de cuña. Hacia el lado E. de esta piedra larga se encontraron dos monolitos menores como desprendidos violentamente del cerco. El espacio comprendido entre las dos primeras grandes mide $9.70 \mathrm{~m}$. y el corte practicado en este sitio hasta el nivel correspondiente a la base o cimiento del muro puso de manifiesto que los dos altos monolitos habían sido enclavados en el macizo de piedras y barro endurecido hasta la profundidad de dos metros. Encima de este macizo se encontró una hilera de piedras, casi tođas del mismo tamaño, cubierta con una capa gruesa de basura. Esta es la misma que aparece en el corte del lado oriental y que se continúa también a lo largo del occidental. La composición de esta capa de basura no es uniforme: en su mitad inferior está muy mezcladacionltierra yearena y en la superior contiene fragmentos de alfarería utilitaria $y$ muches restos orgánicos. Sobre este estrato se halla la tierra suelta del piso superior.

En suma, el examen del corte pone a la vista con toda claridad tres estratos: uno inferior, formado por piedras $y$ barro endurecido en el cual se plantaron los monolitos, cuya superficie es ondulada y algo accidentada, ignorándose la profundidad del estrato; otro medio, formado por una capa gruesa de basura, cuyo espesor es mayor en el lado oriental que en el occidental; y. otro superior, formado por una gruesa capa de tierra suelta mezclada con fragmentos de 
adobes, palos y hojas de algarrobo, mucho mas gruesa al cefitro que en los extremos.

Las observaciones hechas al practicarse las excavaciones -y la clase de materiales arqueológicos adquiriclos, permitieron conocer los sitios donde estuvieron localizados los antiguos edificios adornados con monolitos grabados, la estructura del terreno contiguo a ellos y la clase de fenómenos naturales que alteraron la integridad de estos monumentos, los destruyeron o septiltaron, obligando a conștruír otros nuevos sobre los despojos de los anteriores.

El diagrama adjunto ilustra el resultado de estas observaciones en lo que respecta a las excavaciones practicadas en la mitad oriental de la fachada del. Templo. En este diagrama están marcadas con letras las secciones en que se dividió el terreno para facilidad del trabajo metódico de excavacion. J us monolitos mayores y menores llevan al pie letras y números romanos para su mejor identificación, y detrás de la hilera de monolitos se ven las fajas o estratos correspondientes a tres etapas o períodos, de ocupación de este importante edificio (Din. IV, B).

Los estratos presentan ina superficie ondulacla, elevaciones suaves y depresiones pequeñas, a veces muty extensas. Se puede establecer que la continuidad de estos estratos a lo largo de la fachada, fué rota por excavaciones ulteriores y principalmente por corrientes de agua o lodo bajadas de la falda del cerro vecino.

Se distinguen claramente tres estratos o pisos principales: inferior, medio y superior. El primero está formado por una masa de lodo desecado, de estructura compacta que aprisiona grandes cantidades de guijarros y piedras medianas de aristas cortantes, arrastradas" sin duda por el lodo. Esta masa de barro endurecido es la que forma el relleno del valle, y es una-de làs tantas producidas por las crecientes del 


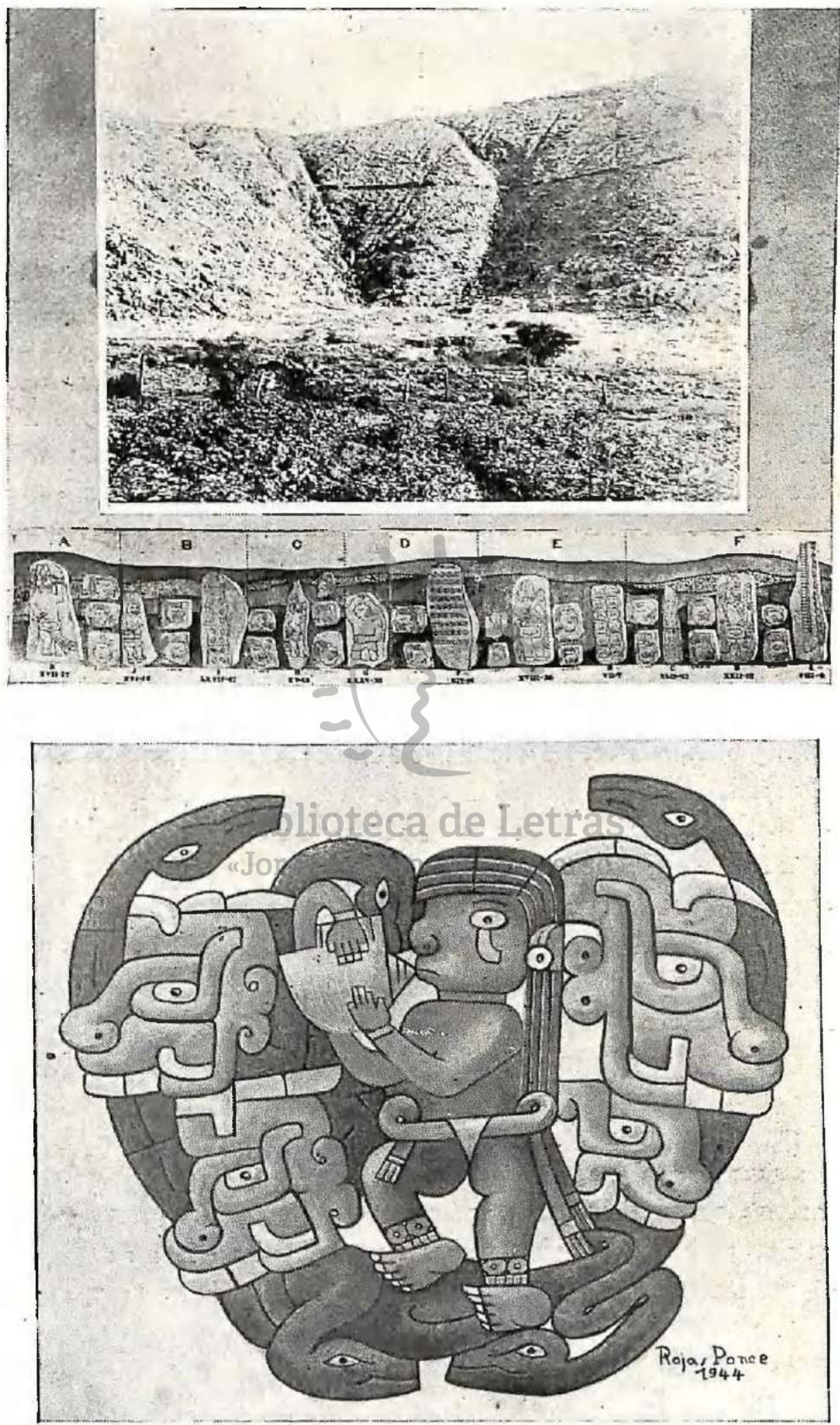

a. La hovacia al pié de Cerjo beehin o de los Corrales doude fueron desenterratios en 1947 estelas liticas adornidis con figuras fintístirns en rejjeve, que apureoen al pie de lil figura.

b. Figura grabula en la cara exterua de ma concla Strombus, Chichya, Lambilyeque. 
$?$

-

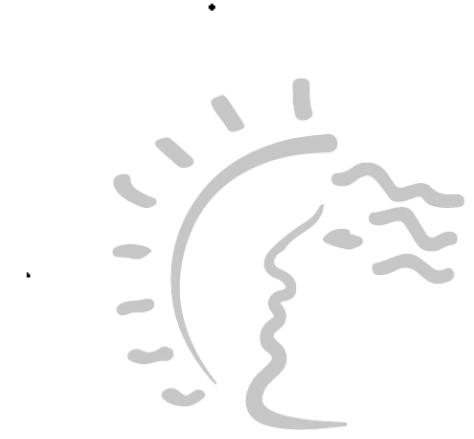

Biblioteca de Letras

"Jorge Puccinelli Converso» 
río, que todavía hasta hoy onđula por la campiña sin hallar su cauce definitivo. Encima de esta capa o asentados dentro de ella se encuentra la hilera de monolitos grabados. Una capa de basura, de espesor variable, y de dispersión discontinua ocupa las ondulaciones de este piso. En ella se encuentran fragmentos de alfarería del tipo Sub-Chavín, restos de cocina y otros materiales en todo semejantes a los que se hallan en el cementerio del Teatino, en el de Supe cerca del Faro, donde años ha trabajara Uhle, en varios de Nepeña y Santa, y en la capa más profunda de un corte practicado por el Río La Leche, cerca de la Waka de Batan Grande. Esta basura, a juzgar por el tipo de alfarería, pertenece a la cultura de Chavín en un segundo período que he llamado Sub-Chavín, $y$-al que pertenecen también las vasijas que Bennet encontrara en el cementerio de Gallinazo, de Virú.

El piso medio está formado por otra gruesa capa de loclo endurecido que aprisiona fragmentos de adobes cónicos, piedras, $y$ aún trozos de paredes enlucidas y pintadas con dibujos polícromos. Tiene un espesor muy desigual. Cerca del centro alcanza hasta $20 \mathrm{~m}$. yalejos de este, Solamente 0.20 $\mathrm{cm}$. El curso de esta masa, cresto de viejas inundaciones, es distinto y opuesto al de la inundación anterior. En este corre del río hacia el pié del cerro, y en aquel del pié del cerro hacia el río. Probablemente lluvias torrenciales bajadas por las faldas del cerro inundaron el áea edificada derrumbaron los edificios, y favorecidos por la impermeabilidad de la roca granítica del subsuelo, se deslizaron hacia el fondo del valle, volteando y arrancando los monolitos de sus cimientos y arrojándolos a veces hasta dos y tres metros. El lodo que oculta tales monolitos, la impresión que cada uno al caer ha dejado sobre dicho lodo, la posición desordena, inclinada y arrastrada de casi todos ellos, lleva al convencimiento de que en un período muy lejano el' edificio adornado con monoli- 
tos fué sepultado por una avalancha aluviónica. Como en el piso anterior, sobre la superficie de éste se encuentra también abundante basura y algunas tumbas con un contenido de alfarería del tipo Santa, o Huaylas-Yunga. Este tipo difiere del Sub-Chavín aunque mantiene ciertos caracteres de filiación, y difiere mucho más aún del tipo clásico Chavín.

El piso superior tiene una constitución distinta de la de los anteriores. El terreno es relativamente flojo: tierra, arena, ripio y guijarros. Sobre él se encuentran restos de terrazas y otras estructuras de piedras rústicas y de adobes rectangulares, y cadáveres con alfarería del tipo Sub-Chimú, Sub-Santa, Inka, y un tipo nuevo de alfarería incisa que aparece en los depósitos superficiales de basura de casi todo el valle de Casma.

Habiéndose aclarado el curso rectilíneo de los monolitos de uno a otro extremo, o sea entre las depresiones que parecen limitar por los lados una plataforma, procedí a explorar el terreno que se halla inmediatamente detrás de la parte media del muro y de sus extremos Este y Ocste. Para ello practiqué varrios cateos en la supuesta plataforma obteniendo el siguiente resultado:

I. - - El muro principal que constituye la fachada del edificio mide $52 \mathrm{~m}$. đe longitud y voltea hacia atrás en ambos extremos formando una curva en la esquina. Mantiene siempre su mismo nivel, penetrando por debajo de las gruesas capas de basura y de los edificios levantadas sobre éstas posteriormente.

2. - Aunque los muros laterales están bien conservados se puede asegurar que la obra es de segunda mano. Los que la fabricaron no dieron importancia a las piedras grabadas pertenecientes a edificios antiguos; ellas fueron utilizadtas 
como meros materiales de construcción, o quizás de ornamentación, sin tener conciencia de su significado. Los monolitos mayores y menores fueron colocados descuidadamente y a distintos niveles dentro de la estructura del muro. Algunos de los monolitos con cabezas humanas estuvieron puestos al revés; y en un caso, en lugar de un monolito mayor, se había colocado una wanka larga sin grabado.

$3 .^{\circ}$ - Por el lado oriental se encontró que un muro grueso construído con piedras y barro se hallaba adosado perpendicularmente al muro lateral de piedras grabadas. Este muro no es otra cosa que el soporte de una terraza construída a continuación cle la plataforma principal sostenida por el muro de monolitos. Deben ser ambas estructuras de la misma edad.

+. - Las excavaciones de prueba realizadas en ambos flanicos de la plataforma pusieron, por íltimo, de manifiesto que el muro de piedras grabadas se halla debajo de una gruesa capa formada por piedras y barro endurecido, sobre la cual se levantaron terrazas que sirvieron, a la vez, de piso a las numerosas viviendas de la población que se estableció en este lugar mucho tiempo despues que desaparecieran los constructores del muro.

En la Waka Cerro Sechín fueron descubiertos noventiseis monolitos: ochentinueve a lo largo del muro o a poca distancia por delante de él; siete a mayor distancia, a treinta y cuarenta metros al NO., desparramados, volteados y semienterrados.

Hay dos tipos de monolitos: uno alargado y alto; prismático como obelisco, o en forma de tableta, o laja como una estela; y otro irregularmentie cúbico. Al primero se le designa monolito mayor y al segundo monolito menor. 
Las piedras aparentemente proceden de las canteras contiguas a la Waka. Todo el Cerro Sechín es de formación granítica. Al pié y en la falda hay montones de piedras desprendidas del peñón en forma de gruesas láminas o de largas masas prismáticas. Este material ha sido usado por los antiguos en la fabricación de sus edificios y en sus trabajos escultóricos.

Por lo general, en cada monolito menor se descubre una cara de fractura que corresponde a la de desprendimiento del block mayor partido para obtener el tamaño apropiado. Los monolitos mayores y menores fueron seleccionados de acuerdo con las necesidades de la representación. No se descubre en las caras o en sus aristas huella alguna de trabajo preliminar o de adaptación a una forma determinada. No hay talladura o pulimento de la piedra. Aún en la cara plana donde aparece el grabado no hay huellas de nivelación previa de la superficie. Algunas piedras presentan sus caras desiguales por exfoliación o por fractura; sin embargo la figura aparece grabada sobre ellas, sin tener en cuenta tales accidentes que hubieran sido fácilmente eliminados.

Los monolitos mayores tienen un alto de $\mathrm{r} .80 \mathrm{~m}$. a 4.40 m.; y los menores de $0.60 \mathrm{~m}$. a $\mathrm{r} .20 \mathrm{~m}$. Los mayores fueron hallađos caídos o inclinados hacia adelante. Cuatro, entre los más bajos de los mayores, se encontraron casi en posición vertical; uno al E. y tres al O. Los monolitos menores estuvieron unos en posición original dentro del muro, verticalmente colocados o con muy pequeña inclinación hacia adelante; otros, a un metro o metro y medio más alejados como si hubieran sido lanzados desde la parte superior del muro, antes de la caída de los mayores. 


\section{LA ESCULTURA DE LOS MONOLITOS DE CERRO SECHIN}

Los monolitos presentan huellas de una larga exposición. Viejas fracturas de los contornos de la cara principal han comprometido corrientemente la integridad de la figura representada en ella; numerosas y, en ciertos casos, extensas erosiones y exfoliaciones han hecho desaparecer las aristas o las han nivelado desgastándolas. Estas erosiones aparecen también en algunos ejemplares sobre la superficie de la cara principal, a trechos como si la piedra después de haber sido grabađa hubiera sido arrastrada sobre otras pieclras. Entre las piedras fracturadas se observa, en unas que la fractura tuvo lugar antes de su caída, pues, en su extremidad superior aparece incompleta la figura grabada por desprendimiento de uno o más trozos; en otras, la fractura se ha producido al caer y chocar con otras piedras. En este caso existen fracturas conminutas en el extremo superior por estallido. En un caso, la piedra grabada al caer chocó con otra de su misma clase.

La cara principal de casi todas las piedras presenta una capa de pátina ocre, la que se extiende uniformemente por las levaciones, depresiones, surcos y hendiduras.

La técnica empleada en la representación de las figuras grabadas sobre las piedras es uniforme en todas ellas. No se encuentran diferencias fundamentales. Todas parecen haber sido trabajadas por un mismo artista o por artistas entrenados en las normas tecnológicas de una misma escuela. Los surcos, hendiduras y rebajos no ofrecen huellas de heiramientas contundentes. Los surcos son escasos. Las hendiduras anchas han sido producidas por una herramienta que actúa por frotación desgastando la superficie hasta 
ahondarla; el fondo y los bordes cle estas hendicluras revelan él clelicado trabajo de frotación por medio de una herramienta que desgasta la piedra suave y lentamente. Es posible rue esta labor se haya realizado mediante el auxilio clel agua o de alguna otra sustancia que cohesiona la arenilla desgastante dentro del surco y facilita el manejo de la herranienta.

Nada diferente se nota tampoco en los rebajos del fondo de las figuras. La misma herramienta raspa y alisa las aristas de las hendiduras. El trabajo no avanza muy lejos dentro del campo del fondo $\mathrm{y}$ esto es lo que produce su asjecto redondeado o abolsonado semejante al que presentan las piedras almohadilladas y de bordes desgastados por frotación de los sillares del Cusco.

La operación del desgaste lento de la piedra debió estar precedicla por el dibujo incindido de la silueta de la figura. Una ilustración pertinente es la que ofrece el grabado de uno de los monolitos grandes de la parte central del muro. Esta piedral fué escogicla porgue una de sus caras presentaba unāosuperficién pulida casisnegra, debido a una capa cle mica, tal vez espejo de faila, sobre la cual se trazó la figura por incisión y no se realizó trabajo alguno de rebajamiento del fondo, como si hubiera quedado incompleto.

A fin de facilitar el estudio de los monolitos que ornamentan el muro se les ha designado con las letras mayúsculas del alfabeto, partiendo, en cada ala del edificio, del munolito gue marca la entrada, que es a la yez el más alto. Las alas derecha e izquierda, u Oriental y Occiclental, constan de diez monolitos mayores y de diez grupos icle monolitos menores superpuestos e intercalados entre aquellos. A estos últimos se les designa con las letras minúsculas respectivas. 

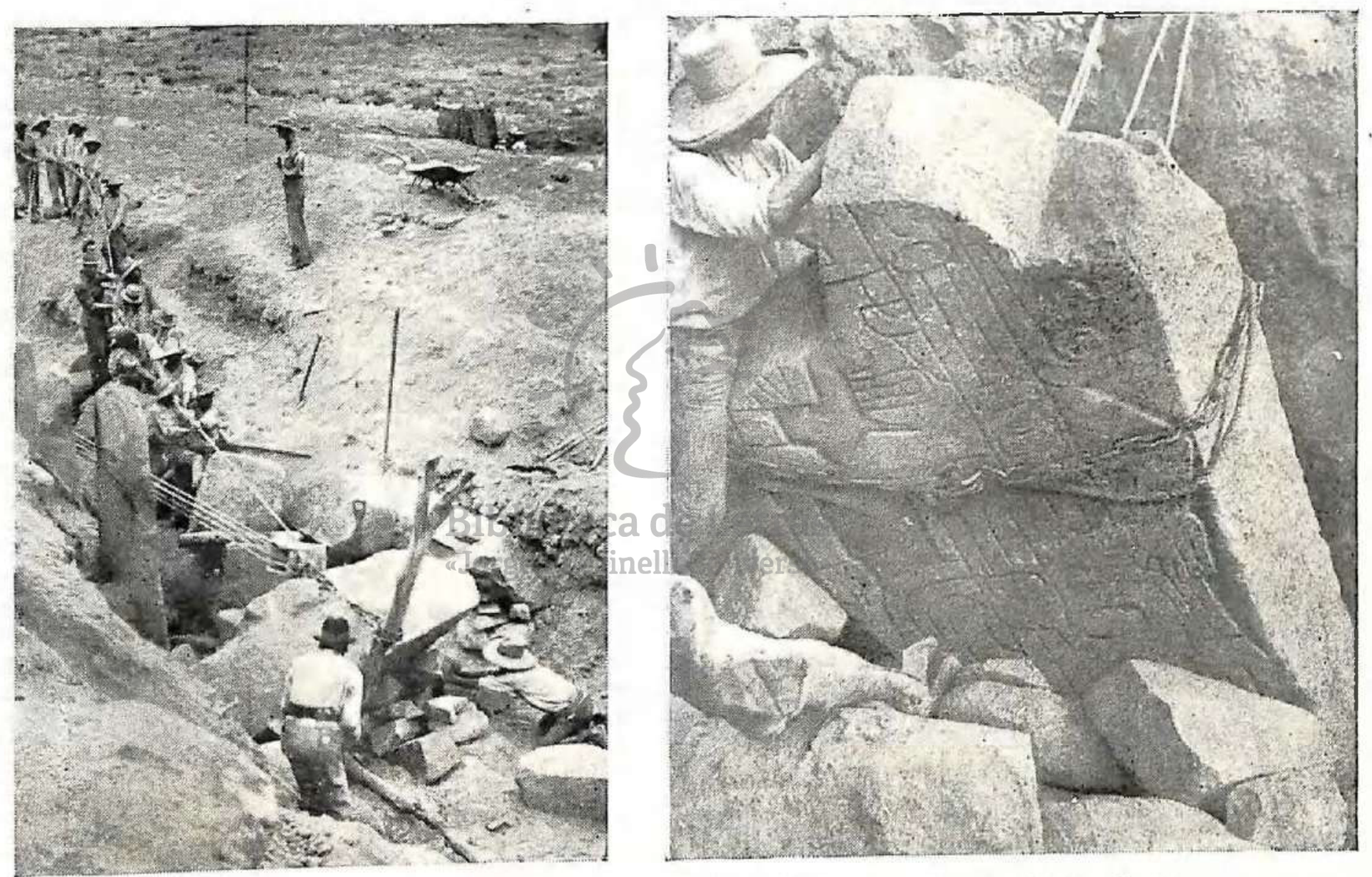

a. y b. Dos etapas en el proceso de descubrimiento de los monolitos en Sechin, Casma 


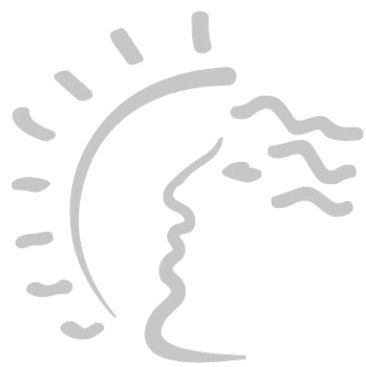

Biblioteca de Letras "Jorge Puccinelli Converso" 
Las figuras representadas enl los monolitos, a excepción de las que adornan los dos más altos del centro, tienen tin mismo carácter figurativo. Todas ellas reproducen la figura humana, completa o parcial, con ciertos rasgos felínicos las que pueden ser clasificadas en tres grupos, a saber: I.-Figuras humanas completas, desnudas o provistas de un sencillo tocado, un cinturón y una herramienta o arma ceremoniaI. II.-Figuras humanas incompletas, seccionadas al nivel de la cintura. III.-Figuras de piezas anatómicas humanas: a) cabezas; b) ojos; c) vértebras; y d) extremidades.

En el cleseo de conocer mejor el sitio arqueológico descubierto al pié del laclo Norte ciel Cerro Sechín practiqué un trabajo cle reconocimiento dentro del área de la tierra cultivada comprendida entre el edificio descubierto y el río Sechín. Este reconocinniento pernitió comprobar la existencia de una extensa clepresión que debió ser un reservorio de agua a poco menos de $25 \mathrm{~m}$. al $\mathrm{N}$. del templo. En las orillas de este reservorio se encontraron restos de muros de piedra sepultados por gruesas capas de bastura y muchos fragmentos de monolitos con figuras grabadas. La basura ocupa una área extensa dentro de la tierra de cultivo y en ciertos sitios forma montículos bajos o plataformas en parte destruídos por inundaciones. Todo hace pensar que un edificio de picclras grabadas semejante al de Cerro Sechín se levantaba sobre el llano entre el río y el pie del cerro y casi a orillas cle dicho reservorio, el cual debió ser inundado, arrastrado y sepultado en una de las tantas crecientes del río.

La figura I, representa una hipotética reconstrucción cie la posición que tuvo el priner monumento $\mathrm{X}$ levantado frente al Cerro Sechín. Al rededor de éste debieron existir muchas viviendas. $\mathrm{Y}$, tal vez oiros edificios mayores. 


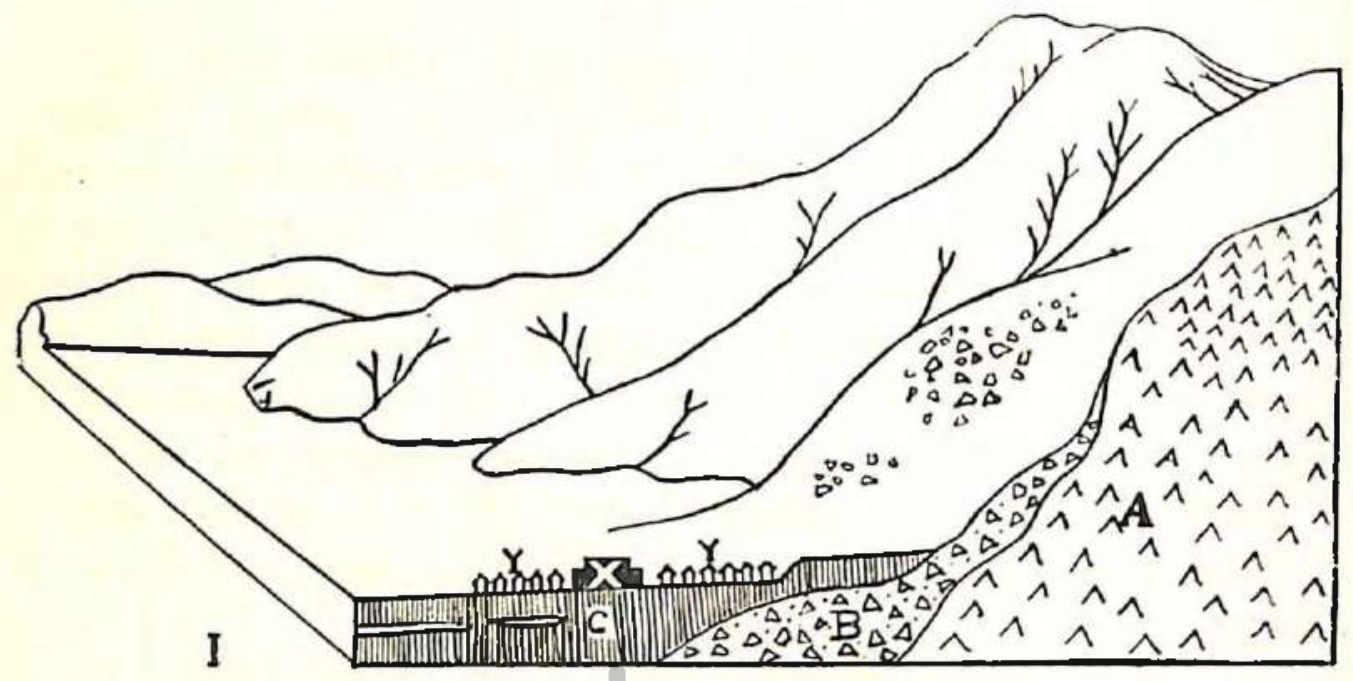

Perfil de la Hoyada del Cerro Sechin (N-S) durante la ocupación del valle por gentes del primer periodo de la cultura Chavin. (Primer periodo). A. Roca granítica; B. Ripio formado por la disgregación de la roca granitica, tierra, barto endusecido y guijartos ancelosos; C. Depósito aluvial rue forma parte ile] relleno iel valle; D. P'iso tormaclo por nntiguay inudacioncs del rio; E. Talud al pie de Ia falda del Cerro Secluin; E. Campo cultivado y basura; $\mathbf{X}$. Restos de antiguos edifieios de tipo Cliavin; $\mathbf{Y}$. Restos de antiguas vivienilas.

Uira intunclación de este-lado del valle sebió producirse después ( fig. II). El loclo cargado de pieclras debió avanzar rellenando la hoyada principal clel pie del cerro, y el terreno resultante de esta intundación $D$ septultó al primitivo edificio $\mathrm{X}$.

Más tarcle se construyó en un piso más alto y más pegado al cerro otro edificio X' (fig. III) aprovechándose para ello de los materiales principalmente de las piedras labraclas que primitivamente formaron parte ciel cdificio X. En esta seguncla etapa de edificación se empleó tun material nuevo: el adobe cónico y la técnica, del enlucido y pintado de las párecles de las cámaras edificaclas dentro del cerco de piedras gralsarlas. Debió mediar un periodo largo entre la erección de tuno $\mathrm{y}$ otro edificio, porque en los contornos de $\mathrm{X}$ aparecen restos de alfarería del tipo clísico Charín, y en los contor- 


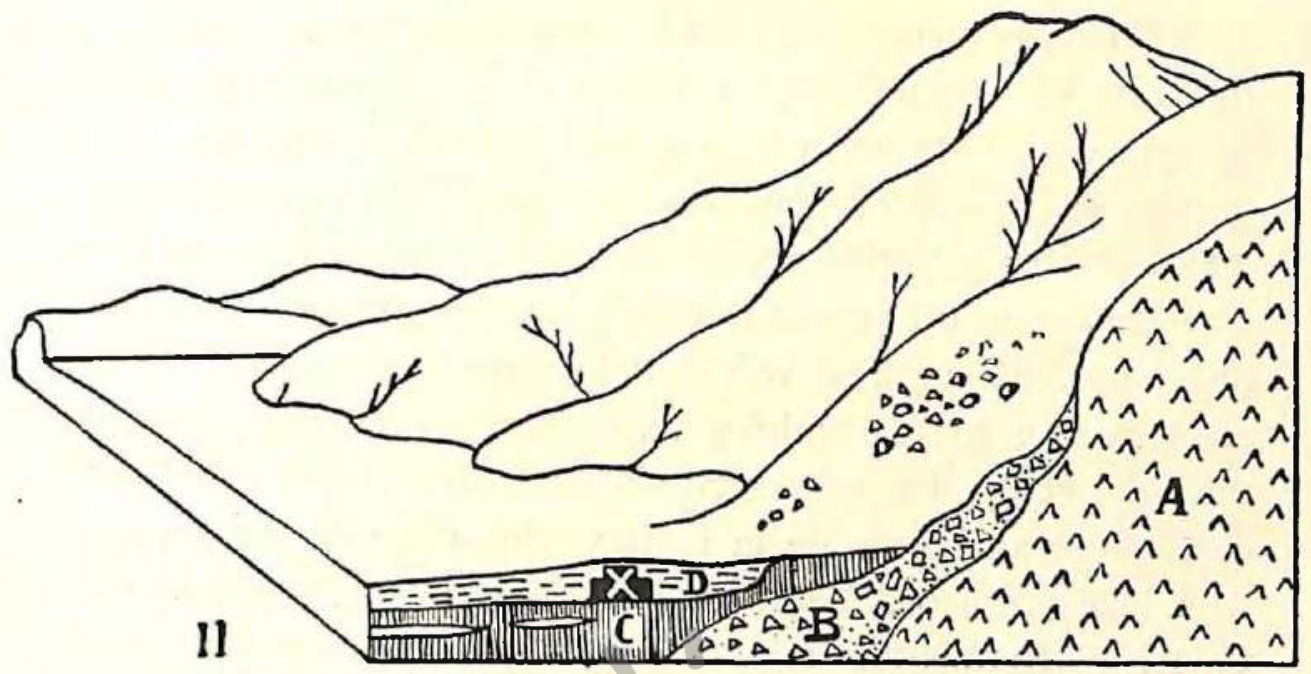

Perfil té la Hoyada después que uma capa aluvínica $D$, la sepultado en parte $y$ destruido los primeros edifieiog Chavm. (Segundo periodo).

110 s de $\mathrm{X}$ del tipo Sub-Chavin. Este tipo clásico Chavin probablemente importado de la Sierra se nodifica considerablemente formando el segundo tipo.

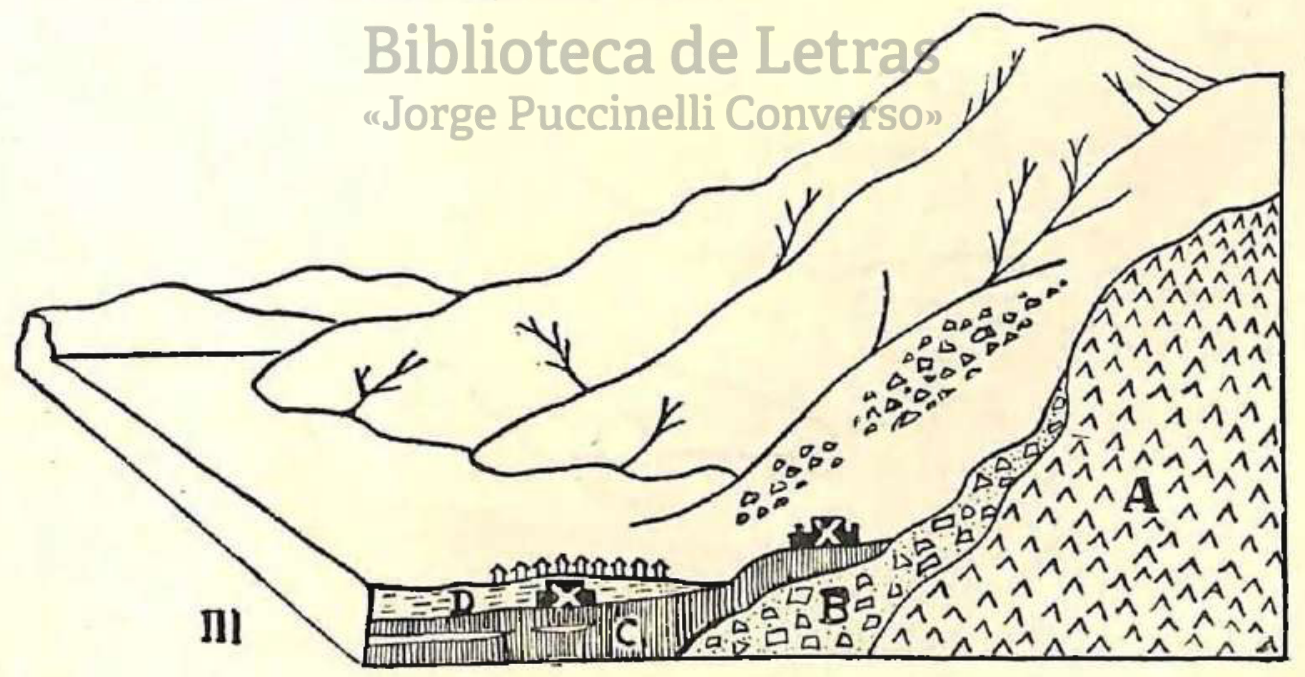

Pertíl de ha Hoyada durinte la oupación del valle por las gentes del seguvalo perículo de la cultura Clavin. 
Posteriormente se produjo otra inundación o mejor un deslizamiento de una gran masa de tierra y cascajo de la falda del cerro. Esta masa F (fig. IV) septtla y destruye el segundo edificio $X '$ ' rellena sus diferentes conpartimientos $y$ los pasadizos y patios protegidas por el cerco de monolitos. Desciende con tal fuerza que desvia a los grandes monolitos de su posición vertical volteánciolos hacia aclelante y aún en ciertos casos arrastrándolos hasta tres metros fuera del límite del cerco. En esta segunda capa de terreno aluviónico se encuentran restos de la cultura Sub-Chavin, fragmentos de adobes cónicos, trozos desprendidos de las paredes pintadas, y fragmentos de alfarería empotrados dentro de la masat de lodo compacto. Parece que restos de esta inumdación fuera la extensa depresión lel terreno y que todavia es hoy terreno pantanoso que en otro tímpo debió ser como ya se ha dicho un reservorio de agtta.

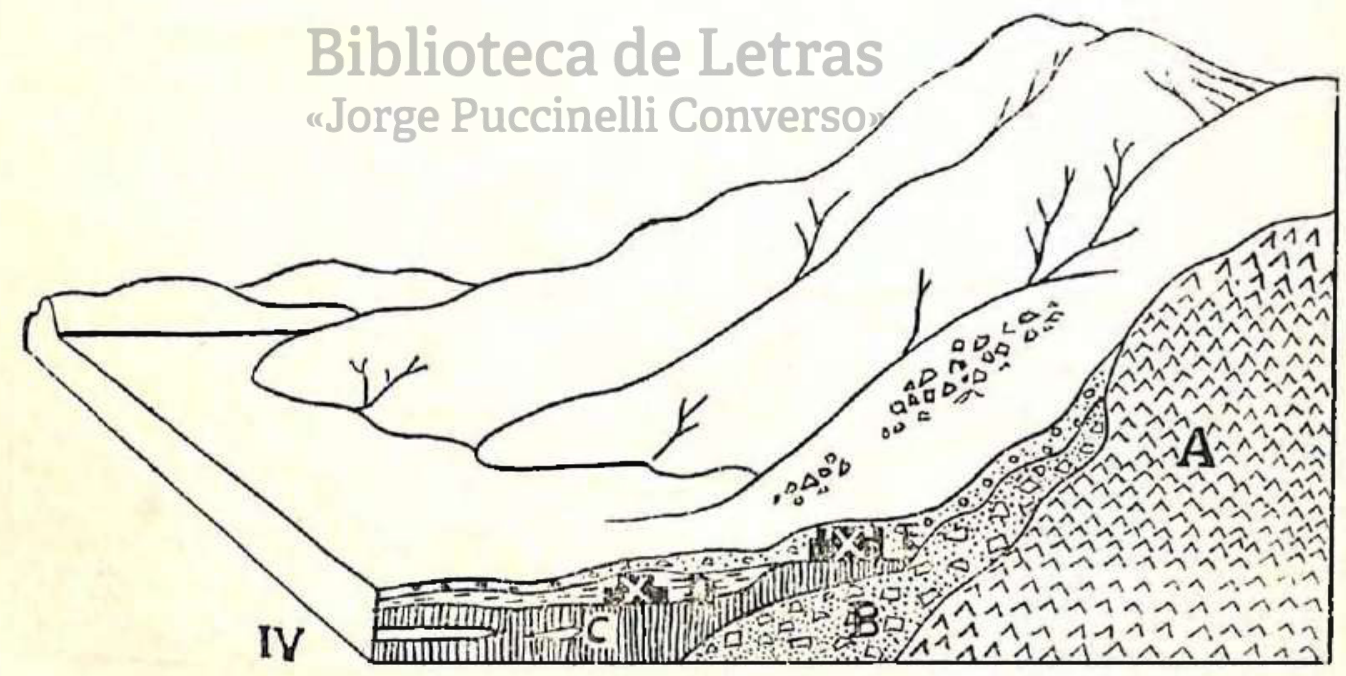

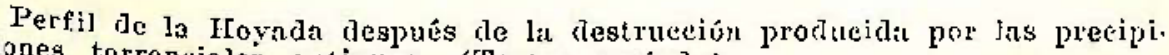
taciones torrentiales antiguas. (Tereer periodo). 


\section{$-3.55-$}

Sobre la capa así formada se construyeron más tarde varias terrazas que sirvieron como platafornas, Y", (figu$\mathrm{ra} V$ ) de viviendas. Las ruinas de éstas se encuentran hoy sepultactas por grandes acumulaciones de basura que cubren tumbas conteniendo cerámica del tipo clásico Santa o Huaylas Yunga. Las lluvias torrenciales habidas en la costa Norte peruana el año I925 formaron arroyos en la falda del cerro que cortaron las capas de basura arrastrándolas a considerable distancia hacia el cauce del río. $\mathrm{Y}$ los huaqueros y buscadores de tesoros han aprovechado de estos cortes para explotar las tumbas habidas en el subsuelo. A esta última inundación se debe también el afloramiento de algunas piedras del cerco que nos sirviera de guía para emprender excavaciones en este lugar. La figura VI ofrece una ilustración de la total disposición de los diferentes estratos que constituryen este sitio arqueológico, a la luz de las observaciones obtenicias mediante múltiples excavaciones de prueba.

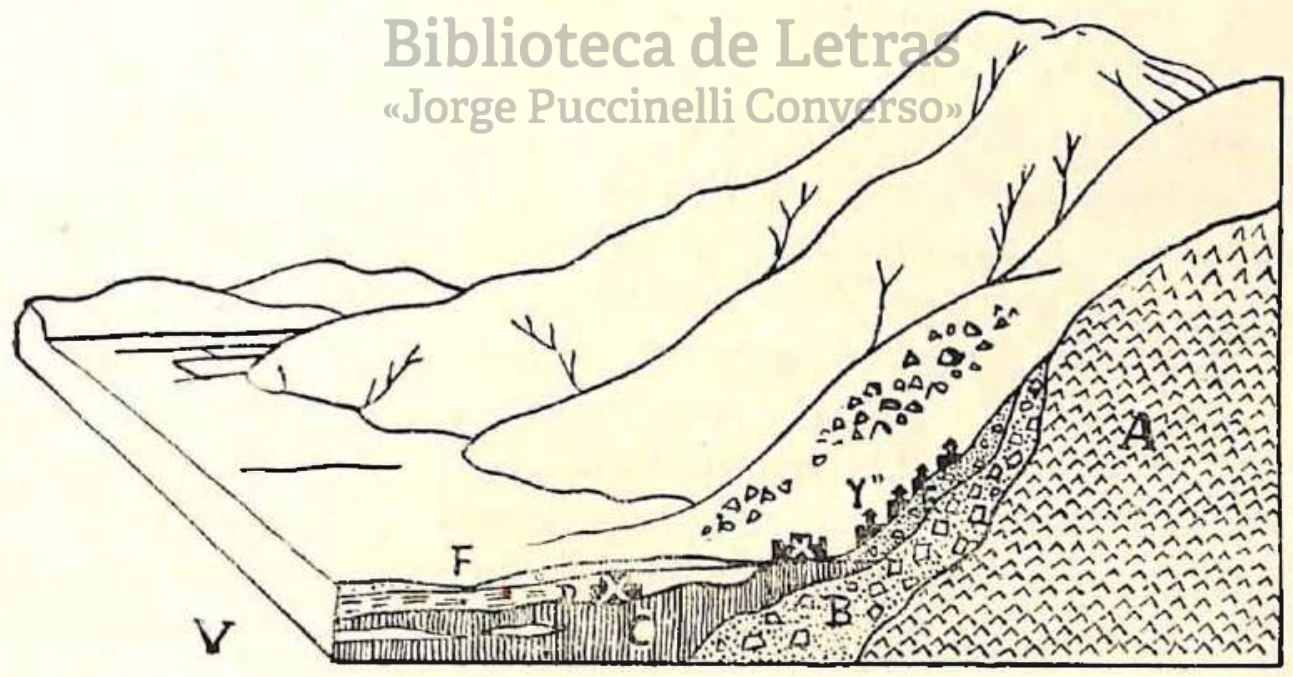

Pcrtil de la Toyada duraute la ocupación del valle por las gentes dal Tercer Periodo. Cultura Sauta-Casma. 


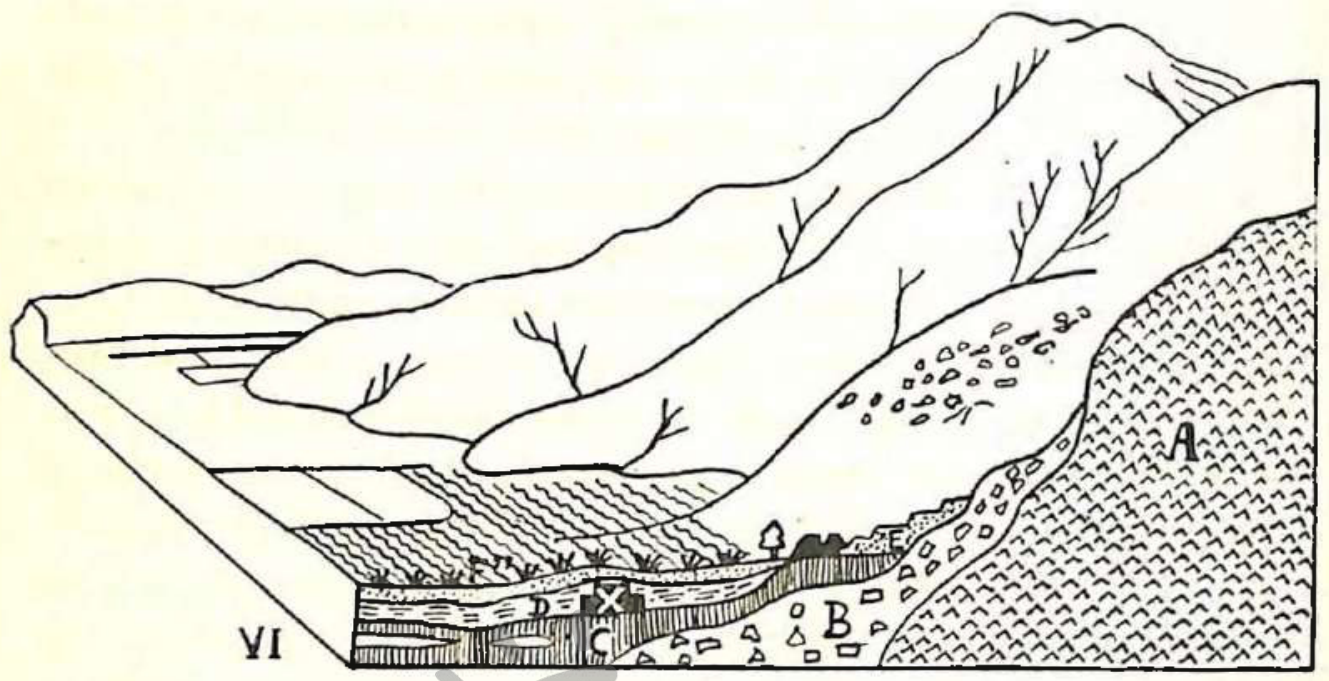

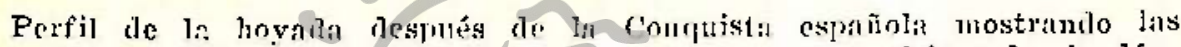
excavapiones realizadias pou los buseardotes de tesorns y los cultivos de algorlít,

\section{TIPOS DF ESTRUCTURAS CHAVIN EN LA COSTA}

Tipos de estructuras majores y menores-Pocu se sabe sobre las estructuras menores pertenecientes a la cultura Chavin; los restos de alfarería Chavin aparecen en ciertos muladares, "que son fos únicos testimonios de habitabilidad htumana. Posiblemente viviendas o chozas construídas con materiales destructibles, con piedras pequeñas y barro, fueron levantadas sobre o cerca del área ocupada hoy por los muladares. En unos casos montones de piedras formanclo rectángulos o círculos y pequeñas terrazas, parecen indicar restos de viviendas, que podrían atribuírse a la cultura Chavin, puesto que en sti superficie se encuentra trozos de alfarería de este tipo. Pero lo más interesante es que debajo de estos restos de viviendas, y ocultas por lo general por la basura o por grandes acumulaciones de piedras, se encuentran las tumbas de tipo Chavin. Por consiguiente la 
costumbre tan generalizada en la costa peruana de enterrar a los muertos cerca de las poblaciones y aún en el interior de ellas, debe ser muy antigua.

$E_{12}$ lo que respecta a las cstructuras mayores se descubre que hay un tipo más o menos uniforme en el plan de erlificación que se reconoce con facilidad sobre todo en la costa peruana. Una muralla o cerco rectangular de piedra sirve cle defensa o protección a una estructura principal que casi siempre ocupa el centro, y a otras pequeñs estructuras a los lados de ćsta, asociada a tumbas. La estructura principal es de picdra o cle adobe, y está construída mediante la superposición de dos y más terrazas o pequeñas plataformas, $y$ sobre la blime terraza hay lina estructura generalmente construida con adobes cónicos. No se puede aún determinar es esilo estructural de este edificio principal porque se ha$11 a$ a veces totalnente derrumbado, o en su mayor parte cortado y saqueadio por los buscadores de tesoros, de modo que apenas es posible identiticar las plataformas, las piedras de revestimicnto a de lsoperte de éstas que forman paramentos más o menos altos o bien mivelados, y las acumulaciones de adobes que son restos de las estructuras, correspondierites a la mezunital propiamente dicha.

Así misino, poco se conoce sobre las estructuras menores salvo los escasos restos repartidos dentro del área cercada. La muralla en la costa es de jiedra y barro. Este tipo de estructuras mayores integrado por uin cerco rectangular $y$ por edificios menores en su interior, entre los cuales se destaca uno mayor que es el templo propiamente dicho, es caractetístico y se hallaba tan arraigado dentro de la mente de los antiguos constructores, que en ciertos casos en que el terreno era demasiado quebrado para la construcción del 


\section{$-3.8-$}

cerco, de acuerdo con el plan pre-establecido. éste era construido aún en la falela de las colinas.

Confirmada la propagacion de la cultura Chavin a la Costa por los hallazgos ya indicados, quedaba todavia por resolver tu problimá de importancial. La alfarería del tipo clásico Chavín hallada en la costa tenia una átea muy inserura. Como de tiempo ch tiempo se encontraban casos aislados o esporádicos, se pensó yue podían corresponder a colonias de gentes del otro larlo de los Andes que incidentaimente hubieran habitario la costa portando sus prorluctos del interior. Más allá de là Corrlillera Negra sin embarô, no se encontraba por ninguna parte tal clase de alfarería. -Acaso la alfareria Clavín cra en la costa más antigua que en la sierra? id scultura lítica Chavin era acaso de menoi edad que la cultura del adobe cónico del litoral? He aqui algunos datos que ayudan aclarar en parte estas dudas.

\section{ALFARERIA EN EL SUBSUELO DE CHAVIN DE HUANTAR}

L1 año deanofocogien los campos de cultivo bajo lav cuales se encuentra seputalo el granotempylo de Chavin de Huántar y en los desmontes separados por mi para clescuurir la escalera de! pabelkn principal, numerosns fragmentos de altarería negra, bruni, blanca y roja, muy scmejantes a la alfarería thilitaria que aparece en la superficie de las ruinas del Callejón de Huaylas. No hallé, entonces, aqui un so10 ejemplar de alfareria Chavin, ni tampoco en el abundante. basural que se extiende hácia el lado $\mathrm{N}$. de las ruinas y muy cerca de la margen del río Wacheska. En agosto de 1934 visité Chavín por segunda vez. Inas lluvias tortenciales habidas periódicamente en los años posteriores a Igrg habian cambiado el lecho del rio Mariash, en cuya margen i\%- 
yuierda st halla Chavin. El bravo torrente de este rio, acercinclose a las ruinas habia desmoronado y arrastrado gran parte de tuno de los pabellones principales. En los últimos :trios cominuó socavando torazmente el templo y ahonctando su cauce por debajo del nivel de los cimientos del edificio. El monumento años atrás intacto habia sido pues destruido casi en un tercio de su volumen; sus escombros arrastrados por el rio $y$ sus cimicntos minados. Al contemplar las averias causadas por el rio tuve, sin embargo, una rrata sorpresa: en las capas más profundas del acantilado descubrí un grueso filón de basura conteniendo multituxl de restos de luesos hummanos y de llama, y abondante cantidad de fragmentos de la alfareria tantas veces buscada en la región andina, $y$ sólo hallada como casos aberrantes en el I.i. toral. Extraje cle este filon de bastra, y de otios pisos aún mis hajos, situados en el sub-suelo de las construcciones megalíticas, un rico e jlustrativo material de alfareria clásica Chavin: alfareria nesra azabache bien pulida y brillante como loza; ilfarería brunácez chocolate, y aliajería rle color rojo vivo con ornamentaciones incindidas $y$ grabadas, tal cono aparecen en Jas mejores obras de piedra rle este maravilloso arte Chavin: todo este material sepultado bajo grutesas capas aluviónicas desprendidas de la fạlda del cerro vecino.

Este hallizgro contribuyó a conocer mejor las características de la cultura Chavín, y a familiarizarse con los aspectos tecnolígico, morfolósico, ornamental y representativo de su cerámicál. Permitió además apreciat ciertos datos relacionados con el alto grado de sti elaboración y de sta antigua edad. I a alfareria se hallo debajo del piso aluviónico sobre el cual se erigieron las estructuras megnlíticas del tem- 
plo, lo que hace pensar que hay también aquí tha superposición de estructuras correspondientes a otros tantos períodos y que las estructuras del piso inferior han sido erigidats por las gentes que a la vez fueron escultores y alfareros, cuyas ruinas han sido sepultadas por capas aluviales y por las ntevas estructuras levantadas sobre éllas.

\section{MOKAN Y BOTOSE}

Otros nuevos hallazgos han venido a ampliar un pord mís el horizonte de esta cultura. Mientras yó exploraba Chavín, Toribio Mejía Xesspe descubría al pié del Cerro Colorado, a $55 \mathrm{~km}$, al $\mathrm{N}$. de la hacienda Mocán, valle de Clicama, una perqueña paskana o paraciero situaclo junto al camino antiguo de penetracion a la sierra de Contumazí. Ent este paradero halló salpicada en la superfice tuna buena can. tidad de fragmentos de alfareria Chavín mezclada con otros de tipo utilitario Chimú. Esta cerámica es menos rica en decoración que la clásica; es uniformemente negra y grisútcea como ella, pero su estilo es marcadamente Chavín.

Entre los fragmentos de allareria extraídos del subsuelo del templo de Chavín de Huantar habían algunos semejantes a los tipos incindidos y grabados de la Amazonía que Nordenskiold consideraba como los más antiguos. Este hecho unido a las noticias publicadas por los misioneros franciscanos sobre la existencia de alfarería negra, fina y grabada en los alrededores de San Luis de Shuaro, cuenca dcl Perené, me indujo al año sigttiente de 1935 a hacer un viaje de inspección arqueológica a las cabeceras de los ríos Marañón, Huallaga y Ucayali. En los alredeclores de la ciudad de Huánuco encontré varios montículos artificiales cuya superficie estaba salpicada con fragmentos de alfareria Cha- 


\section{$-39_{1}-$}

vin, y en uno de ellos, llatnado Wata de Kotosh, cortado años atrás hasta su base por los buscadores de tesoros, hallé en las capas inferiores del corte abundantes fragmentos re alfareria Chavin mezclarlos con otros tipos muy semejantes por un lado al inciso y pintado de las Cavernas de Paracas y por otro al inciso y grabado de la Amazonía.

\section{- PUKARA}

En Octubre de r9.35 pase algunos dias en Pukara, pue- blo de la Provincia de Lampa situado en la margen derecha ve las cabeccras del rio de su nombre, pequeño tributario del Lago Titicaca. Este lugar es tun antiguo centro de fabricación cle alfarcría y muy afamadio por las esculturas, estatuas y relieves de piedra de lit antigiiedad que existen en sus contornos.

La moderna población de Pukara se levanta sobre una extensa terraza aluviónica que en parte sepulta otra población de área mayor cuyos restos diseminados sobre el llano, se destacan en forma de monticulos y te hileras de piedras paradas dispuestas én circulos yn fectángulos. Algunas de estas piedras están talladas, pulidas y grabadas con figuras en gran parte análogas a las que aparecen en los monolitos de Chavin. Los naturales de Pukara fabrican actualmente vasijas de barro: en stus clozas se encucrtran los utensilios y materiales de este arte en actividad. La tierra que emplean para preparar el barro y el adobe con que construyen sus casas; la tierra que remueven para sus sembrios contiene un gran muestrario de alfarería del tipo clásico Inka. El arado pone á la vista alfareria mezclada con tierra y cascajo. Paseando por las estrechas calles del pueblo se observa que las paredes y cercos están revestidos con los bellos fragmentos 
policronos de cerámica Inkaica, expuestos y limpiados por las lluvias. Si se tratara de determinar la edad de los nonnmentos de Pttkara y la clasc de cultura basándose solo tu el tipo de alfareria que aparece en la superficie o en al stabsuelo removido por el arado, se diría que pertenecen al periodo de los Inkas. Sin embargo, lo que se enctentra en la superficic es completamente distinto de lo que se halla a miyor profundidad.

E1 rio en la incesunte labor de buscar stt cauce ha ido serpenteanclo primero por la !Jankra y ahondindo despues su lecho. En esta action! de curso inestable, y de riesgaste incesaite $y$ acarreo de las formaciones sedimentarias producidas por la naturaleza y por el hombre, pone a veces a! descubierto lo que ellas octltan en stus entranias. La situasión geográfica cle Pukara es algo semejante a la de Chavín; ambas están cubiettas por gruesas capas de arcilla y grava fina descendiclas de las faldas de los montes vecinos $y$ ambas se hallan anenazadas $y$ a veces socavadas por el río. En Pukara puede muy bien suceder lo gue en Chavín; esto es, que las estructuris y los monolitos grabados no pertenezcan a la mistué edad que la alfarería hallada en la superficie; que ellas sean sólo stpervivencias de la cultura sepultacla bajo el aluvión. Estas consideraciones me indujeron a raiz de mi arribo a Pukatri a examinar cuidadosamente ei cauce del río en las scciones más próximas a las ruinas. Alli en los acantilados descubri, como era de esperar, varias capas superpuestas de basura conteniendo rico material arqueológico de la misma clase del hallado en Chavín y Kotosh; multitud de frasmentos de alfarería finísima, incindida, grabada y pintacla, tan bella y, en ciertos aspectos superior a los mejores ejemplares de la alfarería Chavín. EI alunkante naterial recogido en Pukara brinda una nueva 
e ilustrativa contribucion al concituiento del arte megalitico Chavin. La alfareria Puhara es una de las mejores dejivaciones de dicho arte, en eila aparecen cumo motivos ornamentales predominantes las figuras del Jaguar, del buho, del Pez y de la Serpiente, modelados, grabados y dibujados en el estilo Chavin.

\section{ILLIMO: LA VENTANA}

A principios del año de 1937 exploré la región arqueológica del Departamento de Lanibayequte y me fue clable comprobar en una de las secciones del cementerio de La Ventama, clistrito cle Illimo, cortada por el rio La Leche, la presencia de tres pisos o estratos formadios por residuos de la actividud humana: uno superior, correspondiente al periodo último Chimú ; otro medio, cortespondiente al período Pre-Chimú ; y otro inferior. correspondiente al periodo Chavín. En este último estrato encontré restos de alfarería inicinclicla $y$ grabada de los estilos Chavin y Huallaga (Kotosh).

\section{RELACIONES ECUATORIARAS}

Uhle, quién durante los iltimos años trabajó afanosamente en la solución del problema de la expansión y coionización maya en Sud-América, cree que las culturas del norte sudamericano no son sino ramas desprendidas del tronco centro-americano. Para él, las culturas peruanas y ecuatorianas, en sus fases más adelantadas, son otros tantos ramos periféricos del viejo tronco maya. En mi opinión, el problema relativo al origen cent:o-americano de las culturas indinas no puede referirse yá, en rigor, en lo que respecta at estas tiltimas, a las culturas de la Seguuda Edad, como 
Muchik, Nasca y Tiahtanaco Clásicn, que no ofrecen el más. lejano parecido con las centro-americanas, sino a la cultura lítica Chavín que es la única que tiene un lejano pareciclo. con la centro americana. $Y$ la alfarería fina, incisa y pintadar de la sierra acuatoriana que Ulile considera como genuinatmente maya no es otra que alfurería Chavín.

\section{CARACTERISTICAS DE LA CIVILIZACION CHAVIN}

Las investigaciones realizadias hasta aqui sobre la civilización megalítica de Chavín perniten conocer algo de sus características principales y ampliar el horizonte de st área de difusión, no sólo a lo largo de las regiones interandina $y$ trasandina, sino a lo largo del Litoral del Pacífico.

Dentro del dominio territorial Andino ninguna civilizacion tiene carracteres tan definiclos y propios como la $\mathrm{Ci}-$ vilización Chavin. Si centro más importante se haila en la cuenca del Alto Marañón; y su área de propagación muy exiensà, sobrepasa los límites del Norte Andino. Donde quieta que se encuentre restos de ella, cualquiera que sea la obra edificada o mbutifacturada, ola materia Sprima usada: picdra, metal, hueso, arcillaco algtina otra que liaya resisticlo la acción del tiempo, allí están presentes las vigorosas e inconfundibles creaciones arquitectónicas, escultóricas o pictóricas. de una raza extraordinaria, cuyo nombre y recuerclo se hà borrado de la memoria de los hombres en el correr de los siglos; pero que ha dejado los restos innegables de su civilización, tan propia y original, que no tiene parangón entre las otras civilizaciones prehistóricas sudamericanas.

Son manifestaciones consideradas como propias de la Civilización Chavín las siguientes:

r.--Edificios de piedra agrupados en ciudadelas amuralladas; templos pirámidales formados por una o más pla- 
taformas superpuestas atravesadas con galerías interiores y rellenadas con piedra y barro; y cámaras especiales o adoratorios propiamente dichos en la parte superior a los que se alcanza mediante escaleras subterráneas de acceso. Las paredes interiores de los adoratorios y de las galerías frecuentemente revestidas con una capa gruesa de arcilla endurecida a fuego. Este procedimiento de calcinación del barro se aplica también a los estucados y relieves modelados que decoran los paramentos de cámaras y altares. La fachada de ciertos edificios como la del Templo de Chavín de Huantar, protegida por un alto zócalo de lajas labradas y pulidas, y los paramentos de toda la construcción revestidos con piedras rectangulares dispuestas en hileras horizontales en las que alternan dos hileras de piedras delgadas con una de piedras anchas.

En los edificios descubiertos en el Callejón de Huaylas como en Pomakayan cerca de Huaraz, las estructuras propiamente Chavin están ocultas por las de Recuay lo que prueba superposición de edificios de distinta época. En otros de la Costa, como en los de Sechin Alto y Moxeke en Casma y Cerro Blanco y Punkturi en Nepeña, se ứa el adobe cónico para el relleno de las subestructuras, el barro para construir ídolos de grandes dimensiones colocados en los nichos y para modelar los arabescos que adornan los interiores de las cámaras, y la pintura para los frescos murales. El adobe y la escultura plástica, aparentemente propios de la Costa, no excluyen la escultura lítica tan característica del arte Chavíis, revelada como en el caso de Cerro Sechín en los numerosos monolitos que forman el cerco de la gran plataforma o subestructura del Templo.

2.- -Obras escultóricas exponentes de un arte lítico avanzado; figuras grabadas en alto y bajo relieve, estatuas 


\section{$-366-$}

que se enctientran adornando sus templos y multitud de utensilios de piedra dentro de sus tumbas. Sobresalen en este arte las estelas y obeliscos $y$ las cabezas clavas que reproditcen seres fantásticos (Laminas VI y VII.): dragones zoomorfos y ornitonorfos, ctyos hallazgos se han multiplicado ein los tíltimos tiempos no solo en la Sierra sino en la Costa, comio los relieves de Cerro Sechín que representan fignras humanas cadavéricas, clierpos humanos descuartizados: cabezas, ojos, brazos, piernas y huesos de la columna vertebral...

3.- Cerámica consistente en recipientes monocromos, negros, grises, y rojos que a primera vista hacen la impresión de vasijas de madera o de piedra, o fabricadas haciendo uso de un material duro y con herramientas apropiadas para el taladro, el rebaje, las incisiones y en general para el esculpiclo de las figuras que las ornamentan. El cuerpo del cántaro es macizo. de contornos acentuados, globular o ea ciertos"casos" con stiperficies facetadas y aristas salientes; de basé plana; cuello gruéso tubular arqueado; labios expandidos imitando el tallado en madera o piedra; los bordes de los platós y bocas de las ollas, gruesos y cortados a bisel. Esta. clase de vasijas están ornamentadas con líneas incindidas rectas o curvas, con trazos al grafito en el fondo de la incisión en el caso de las cle color rojo; con hileras de triángulos escalonados o líneas cruzaclas cue forman. paños re'ticulados, supervivencias tal "vez de las redes o mallas de maguey que protegian los recipientes de madera arquetipos con trazos incisos ejecutados en el barro, antes y después de la coeción, con decotaciones acanaladas y plizadas, con puncturas y escarificaciones y con plano, bajo,y :alto. relie'ves, imitando en todo, por su forma, técnica, y. ornamentación, a las vasijas : de :madera: 
LETRAS Vol. 26 .

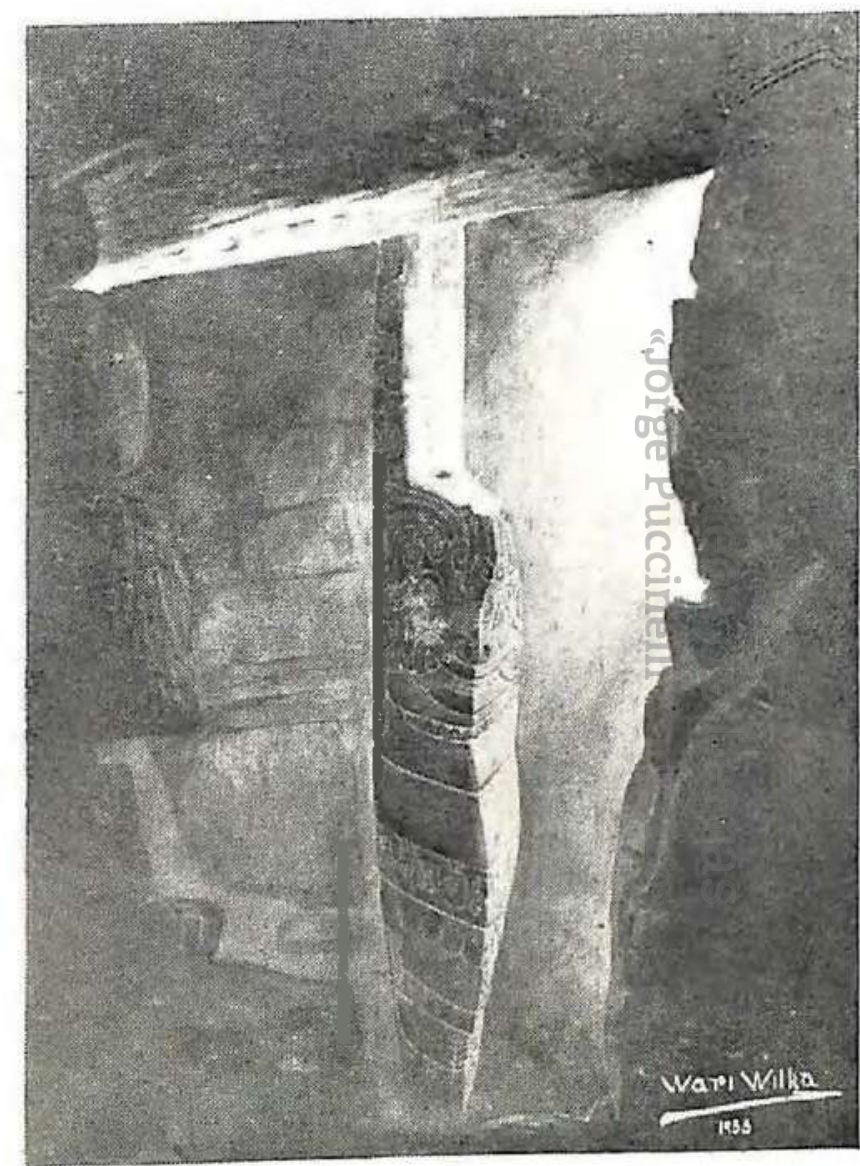

(Tello) Limina VI

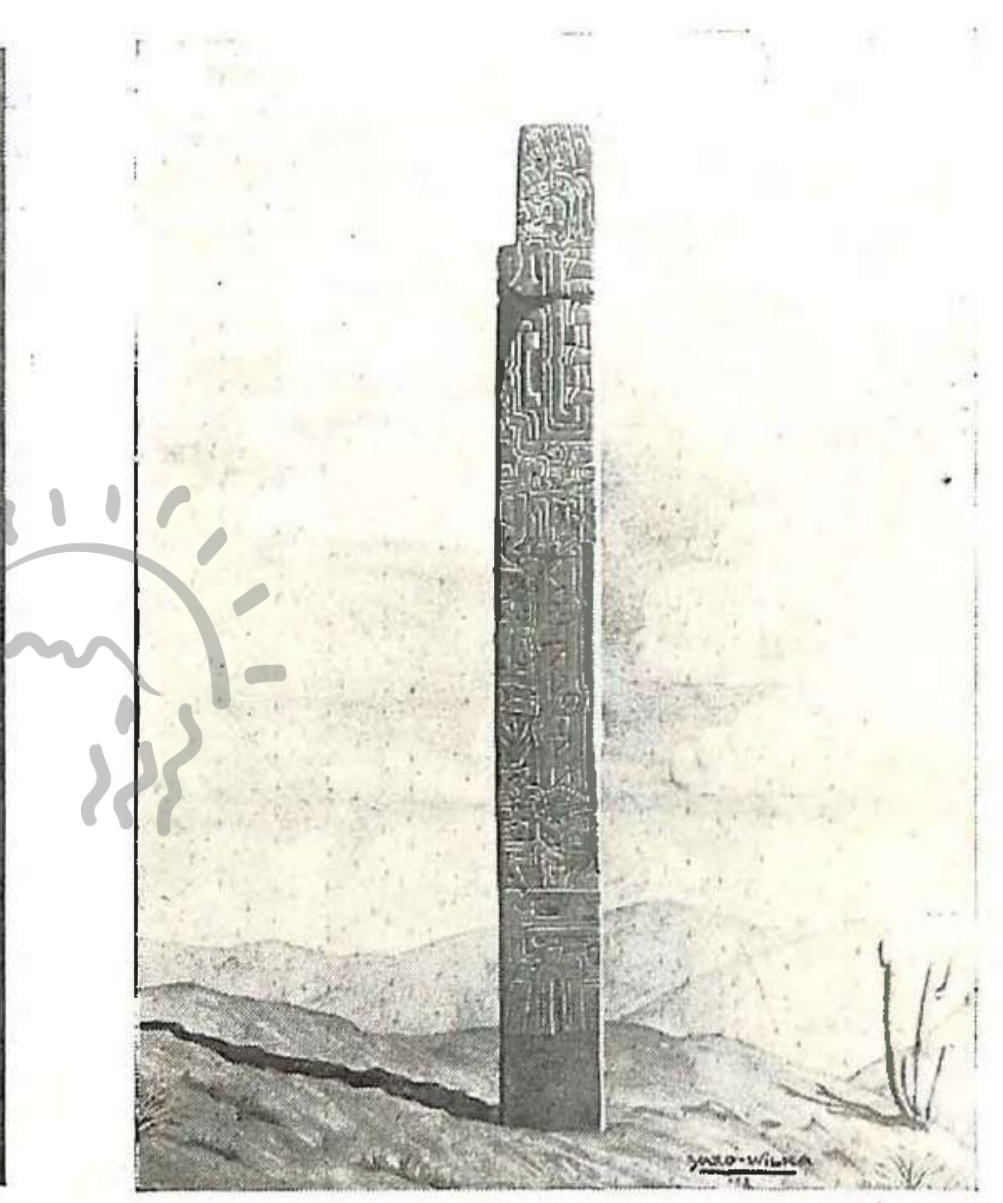

a. Lanzón, b. Obeliseo, encontrados en el Templo de Chavín de Huantur 


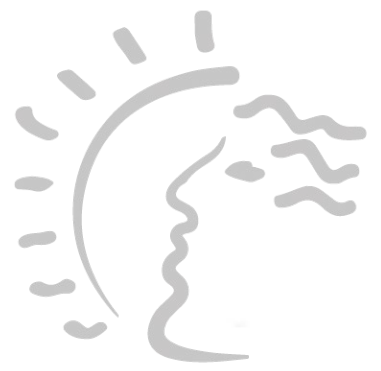

Biblioteca de Letras "Jorge Puccinelli Converso" 
4.-Representaciones de seres demoniacos o míticos, estructurados a base del tratamiento de un motivo fundamental: la cabeza del felino. Ellos son:

a-Un dragón de cuerpo alargado, hocico armado con grandes colmillos y patas con garras, que semeja un cococrilo. Este monstruo es hermafrodita y lleva en el vientre una enorme boca con colmillos y en las patas manojos de yucas y ají. Tiene como asociados en la misma alegoría a tres animales: un felino, un pez y un ave, buitre o buho. Su mejor ilustración es la que adorna el obelisco hallado años atrás en el centro de la plaza principal del Templo de Chavín, hoy en el Museo de la Universidad (Lám. VI, b), y el tablón con figuras de un dragón felinoide que revestía una de las cámaras interiores del Templo (Lám. VII, a.).

$\mathrm{b}-U n$ monstruo fclinoide antropomorfizado, que tiene como mođelo arquetipo el felino que acompaña al dragón. Su mejor ilustración es la figura que aparece en la estela Raimondi, hoy en el Museo de Arqueología Peruana y el Lanzón que se halla en una cámara del templo de Chavín. (Lám. VI, a.).

c - Un monstruo ornitomorfo humanizado, que es la misma ave que acompaña al dragón, cuyo cuerpo está estructurado mediante la transformación de los detalles morfológicos del animal, como las remiges, rectrices, rostro y garras, en serpientes y cabezas de felino, reproducidas parcial o totalmente. Magníficas ilustraciones de este monstruo alado se hallan en varias estelas completas e incompletas de Chavín, reproducidas hoy en yeso y exhibidas en el Museo de Antropología.

$\mathrm{d}$ - Un monstruo ictiomorfo, que es igualmente una representación idealizada del pez que acompaña al dragón. 
Como en el caso anterior, los detalles morfológicos del aninal, rostro, escamas y aletas, están transformados en cabezas de felinos. Su mejor ilustración es la gran estela hallada en I9I9 en Yauya, margen derecha del Yanamayo, ctıya réplica se exhibe en el Museo de Arqueología de la Universidad de San Marcos.

e - Felinos humanizados de composición más simple con rasgos generales más humanos aunque de aspecto cadavérico: seres extraños, cabezas y miembros desarticulados, sin las extremidades inferiores y en asociación con brazos, pies, cabezas, ojos y vértebras, como si todas estas partes del cuerpo humano estuvieran vivificadas. Estos seres fantásticos se encuentran en-los relieves del templo de Cerro Sechín y en las lápidas encontvadas en varios sitiós de los alrededores de la cuenca del Pulicha. En algunos casos llevan la cabellera larga y ensortijada; el cráneo cubierto.con un casco con brida y están armados con porras o hachas.

En las ornamentaciones de la cerámica, en los trabajos de orfebreria, en los grabados en hueso y en los múltiples utensilios de piedra se encuentran motivos derivados de la cabeza del felino o de los monstruos anteriormente presentados.

Llama la atención que este arte Chavin se presente tan uniforme y típico en su estilo y en sus múltiples y variadas manifestaciones en sitios alejados de sus centros de mayor desarrollo, manteniendo las caracerísticas de una producción madura, elaborada a base de normas fijas, sin modificaciones sustanciales tan comunes en otras artes que también se han propagado lejos de sus centros de origen.

En rigor, no hay diferencia fundamental entre una pieza de alfarería encontrada en Chavín y otra hallada en la Costa, en el Huallaga o en el Sur. del Ecuador. 


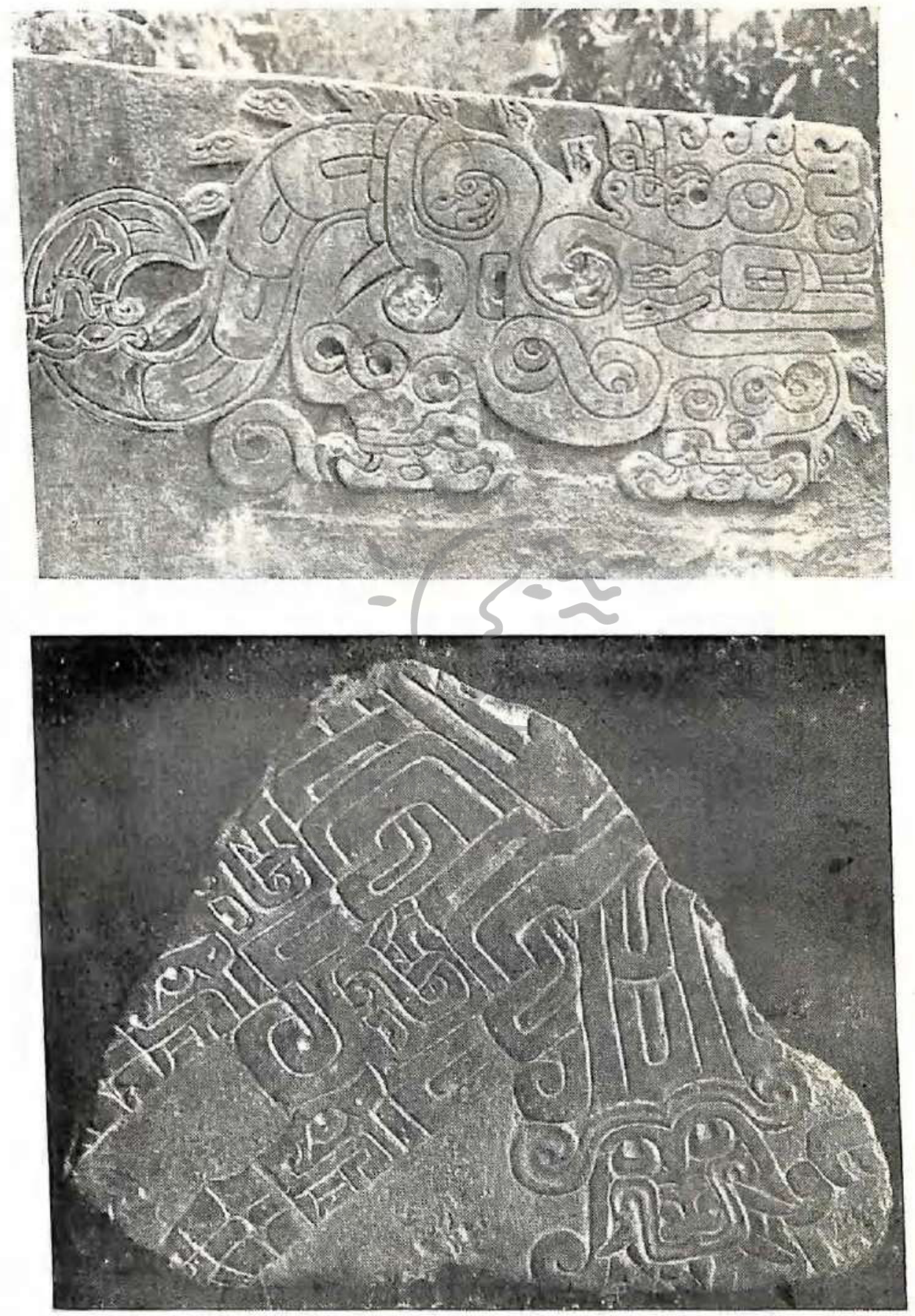

Dos monestras del arte lítiso de Chavin te Fuantar. 
缭 


\section{$-369-$}

En suma, muy poco se conocía de esta civilización antes del año 1919 en que se realizó la primera expedición de la Universidad de San Marcos al importante centro arqueológico de Chavín de Huantar. En los años posteriores, una serie de exploraciones por diferentes lugares del territorio ha dado como resultado el descubrimiento de otros sitios pertenecientes a esta misma civilización, tan importante como Chavín. Templos y extensos yacimientos conteniendo alfarería Chavín han sido identificados en el Callejón de Huaylas: Inka Wain y Ponakayan; en el valle de Santa: Ipuna y Suchiman; en el de Nepeña: Cerro Blanco, Punkuri, Kusi-pampa, Pincha-marka y La Carbonera; en el de Casma: Pallka, Sechin Alto, Cerro Sechin, Moreke, La Cantina y Chantkillo; en los de Pativilca y Supe: Puerto de Supe y Chiwo Kapak; en el de Hutaura: Choke Ispana; en Lachay: tumhas Chavin en el cementerio del Teatino; en Ancón: extensos basurales con cerámica que Uhle consideró como pertenecientes a los pescadores primitivos; en Bellavista, Pachacamac, Cruz de Hueso y Pucusana: basurales conteniendo cerámica Chavín; y por último, en las Cavernas de Paracas y en Ocucaje. Avanzando hacia el Oriente; en la cuenca del Huallaga, principalmente en Kotosh alrededores de la ciudad de Huánuco, en San Luis de Shuaro y Satipo; y en el Marar̃ón: en las cuencas del Yanamayo, Pomabamba, Crisnejas y Chotano donde se hallan: Pasa Kancha, Yauya, Chakas, Kumbemayo, Hualgayoc, Huambos y Pako pampa, respectivamente; hacia el Sur: en la cuenca del Pukara; hacia el Norte por el Litoral, en el Valle de Chicama: Mokan, Sausal y Barbacoa; en el de Lambayeque: La Ventana, Chongoyape y Chiclayo; en el de Piura: Morropónt; y en la región meridional del Ecuador mencionados por Uhle: Cerro 
Narrio, Alausi, Puntos de Nar, Cuenca, Sigsig, Chordelcg, Saraguro, Chinguilanchi, Rircay y Uchucay; pero considerados por él como sitios de propagación maya.

Los restos de la civilización Chavín se hallan en todas partes sepultados por los de las otras civilizaciones que le sucedieron tan diferentes en su clase como si se tratara de civilizaciones completamente extrañas a ella. Sin embargo ciertos hechos que se exponen a continuación, llevan a suponer la existencia de una etapa de transición entre la civilización de Chavín y la de Recuay-Pasto. En algunos de sus aspectos muestran testimonios que parecen evidenciar que ésta se deriva de aquélla; o bien, que teniendo ambas orígenes diferentes convivieron y se mezclaron por algún tiempo.

En la sierra contigua a la floresta, como en las cuencas del Alto Huallaga y Alto Marañón, se hallan restos Chavín en sus formas clásicas y en toda la riqueza de sus variedades estilísticas. Aparte de las esculturas líticas se encientran en estos centros vasijas decoradas mediante grabados que se suceden desdéla mera incisión o escarificación y punctura hasta el alto y bajo relieve y la escultura en bulto. Este arte de la Sierra oriental tiene su representación también en el del Litoral del Pacífico.

En la morfología de la cerámica Chavín del Litoral, estudiada globalmente, se descubre dos clases de vasijas: una, poliédrica escultórica; y otra, globular pictórica. Estas corresponden a las dos influencias ancestrales, Chavín y Recuay, que las engendran. La primera, de silueta rectilínea con aristas y curvas poco pronunciadas: de gollete cilindrico, curvo, grueso o cónico: paredes gruesas y de ornamentación grabada o esculpida, que imita las vasijas de piedra o 
madera. La segunda, de silueta curvilínea, con gollete ampuloso y ornamentación que comienza con el uso de la técnica negativa y culmina con la pintura policroma.

El arte Chavín de la Costa, aunque mantiene muchas de las formas y ornamentaciones clásicas del arte de la sierra oriental, ofrece otras modalidades de carácter local en los yacimientos o colonias halladas a lo largo del litoral del Pacífico. Así las vasijas extraídas de las tumbas Chavín del Teatino, Lachay, conservan algunas de las formas clásicas y su carácter monocromo, negro o bruno oscuro, y ofrecen formas y ornamentaciones que en culturas posteriores se repiten y copian bajo nuevas técnicas. (I7.)

Otro derivado del arte Chavín es el tipo Nepeña, el mismo que Bennett encontrara en Virú, denominándolo Gallinazo ( I8). En él se encuentran elementos que son de estirpe Chavín: tazas de paredes gruesas y labios ligeramente expandidos, como las encontradas en Ancón y Teatino; cántaros formados por la unión de un casquete y una taza y con gollete grueso, cilindrico o ligeramente campanulado; cántäros globulares con 0 sin pedestal y gollete tubular arqueado, con rodete o expansion labial; figuras humanas de un tipo algo extraño en la costa, pero común en el interior, cle perfiles rectos, paredes igualmente gruesas, color rojo os-

(17) En Teatino, Lachay y en otros cementerios del valle de Chancay he encontrado tumbas conteniendo alfarería monocroma, incisa e indentada, semejante a las halladas en Supe y en Ancón. Yo he designalo a esta alfarería Sub.Chavín porque no aparecen en ella las formas y ornamentación típicas del clásico Chavín, sino esporádicamente y porque son representativas de un tipo de tumbas que pueden considerarse por su contenido como intermediarias entre la cultura clásica Chavín y la cultura de las vasijas policromas de tipo Chancay. Se ha logrado establecer la estrecha vinculación genética de este tipo sub-Chavín entre el Chavín clásico por un lado y el policromo Chancay por el otro.

(18) Wendell C. Bennett, "Archaeology of the North C'oast of Perú". Amer. Mus. Nat. Hist. XXXVII, Part. I, New York, 1939, fig. 13. 


\section{$-372-$}

curo, chocolate o blanco, siempre monocromo y en algkinos casos con restos de decoración negativa. Estas vasijas se hallan en tođo el valle de Nepeña y en los contiguos de Casma, Santa y Virú, penetrando dentro del área Muchik. Las ornamentaciones son incisas o con aplicaciones plásticas de cordones con muescas practicadas con la uña. Las vasijas de Pativilca tienen así mismo formas poliédricas y sus ornamentaciones consisten en figuras que reproducen las del clásico Chavín, aunque simplificadas o degeneradas.

Los hallazgos de testimonios del arte Chavín en diferentes lugares del país, comprueban su extensa área ce propagación. El estudio comparativo de estos hallazgos ha dado como resultado la identificación, en sitios alejados de su centro, de los mismos caracteres que definen a este arte clásico. No se trata de meras analogías. Los objetos hallados en la Costa son los mismos que se encuentran en el foco; y la alfarería es la misma en calidad, forma y ornamentación la que se halla en el subsuelo de las estructuras megalític:as del Templo Chavín de Huántar. Otra clase de testimonios hallados en la Costa, como los citados anteriormente, prueban que el arte clásico Chavín influyó, o acaso originó en gran parte el arte de las culturas preincaicas. A este respecto son muy reveladores los hallazgos realizados en las $\mathrm{C}$ ivernas de Paracas. Aquí se encuentra alfarería incisa decorada con pinturas resinosas de diferentes colores y motivos ornamentales que no son otra cosa que los motivos y las figuras demoniacas del arte Chavín. Se han encontrado también restos de alfarería de filiación Chavín en el Interanclino ecuatoriano y en Manta, aunque no en las formas propiamente clásicas. Por el Sur se hallan igualmente pruebas de la influencia Chavín en uno de los centros más importantes de Tiahuanaco, como Pukara; y es posible que el tipo Ba- 
rreal de la alfareria argentina no sea sino tuna de las manifestaciones periféricas de la Civilización Chavín.

En suma, a lat laz de los hechos expuestos, se inede afirmatr, con cierto fundamento, lą existencia de esta cultura megalítica Chavín. Nada nus cuentan cle ella los historiadores y cronistas de Indlias, cuyas obras han sido y son todavia consideradas como las fuentes más seguras de información histórica. Nada nos cuentan tampoco sobre ella los modernos investigadores. Fn las colecciones de las antigüedades peruanas existentes en el Perú y en el extranjero, son todavia escasos los ejemplares representativos de esta olviciada civilización. Sin embargo su existencia es real; las ruinas de sus poblaciones y templos las encontramos, a menudo, sepultadas por aluriones o por otrats estructuras, ccinstruictas posteriormente sobre ellas, formando montículos ạue sc confunden con los montículos y prominencias naturales clel terreno.

\section{Biblioteca de Letros. TruLo.

